\title{
How to Educate Entrepreneurs?
}

Georg von Graevenitz and Richard Weber

\author{
Discussion paper 2011 - 2 \\ July - 2011 \\ Revised - November - 2011
}

Munich School of Management

University of Munich

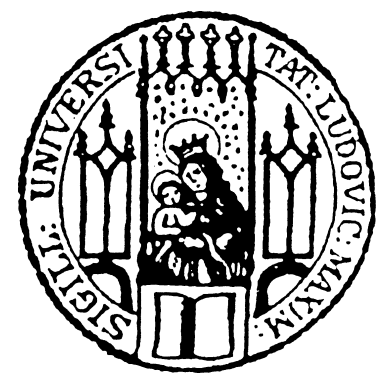

Fakultät für Betriebswirtschaft

Ludwig-Maximilians-Universität München

Online at http://epub.ub.uni-muenchen.de/ 


\title{
How to Educate Entrepreneurs?
}

\author{
Georg von Graevenitz* $\quad$ Richard Weber ${ }^{\dagger}$
}

November 27, 2011

\begin{abstract}
Entrepreneurship education has two effects: it improves students' entrepreneurial skills and provides impetus to those suited to entrepreneurship while discouraging others. While entrepreneurship education helps students to make a vocational decision its effects may conflict for those unsuited to entrepreneurship. We show that vocational and skill formation effects of entrepreneurship education can be identified empirically using a structural equation model. While conflicting effects of vocational and skill directed course content are observed in some individuals, overall these types of content are complements. We discuss how our results extend recent research and provide implications for the design of entrepreneurship courses.
\end{abstract}

JEL: L11, L13, O34

Keywords: Entrepreneurship education, entrepreneurial intention, Theory of Planned Behavior, structural equation models, two stage least squares.

Acknowledgements: Georg von Graevenitz acknowledges the support of the SFB Transregio 15. Also, we would like to thank participants of the 2011 TI:GER workshop for comments and discussion and Marie Thursby for inviting us. Dietmar Harhoff, Albert Maydeu-Olivares, Joachim Henkel, Holger Patzelt, Henry Sauermann and Michael Roach provided valuable feedback. Ken Bollen and Joern Block provided comments on the manuscript which are very grateful for. The usual caveat applies.

*Corresponding author - Ludwig-Maximilians-Universität, LMU Munich School of Management, INNO-tec, Kaulbachstraße 45, D80539, Munich, graevenitz@lmu.de, Tel.: +49 892180 2878, Fax.: +49 8921806284

${ }^{\dagger}$ Ludwig Maximilians Universität, LMU Munich School of Management, LMU EC (Entrepreneurship Center), Kaulbachstraße 45, D-80539, Munich, richard.weber@1mu.de 


\section{Introduction}

Entrepreneurship education is a widespread component of school and university education (Martínez et al., 2010). It is supposed to increase the flow of entrepreneurs (Kuratko, 2005) who are seen as an important source of growth (Sheshinski et al., 2007). However, the real effects of entrepreneurship education on economic growth are most likely more complex than this suggests. For instance, while two recent papers which study entrepreneurship courses at universities find these reduced students' entrepreneurial intentions on average (Oosterbeek et al., 2010; von Graevenitz et al., 2010), this is not always true (Souitaris et al., 2007). von Graevenitz et al. (2010) also show that entrepreneurship education provides students with signals about their entrepreneurial ability, resulting in sorting. Some students learn that they are suited to entrepreneurship, others that they are not. This sorting function of entrepreneurship education matters because more entrepreneurs do not raise growth, contrary to what is sometimes argued (Shane, 2009). Rather, it is specifically the pursuit of high quality entrepreneurial ventures that raises growth.

Sorting explains how even high quality entrepreneurship education may reduce students' average entrepreneurial intentions. While this is useful to know it does not elucidate how entrepreneurship education affects students' entrepreneurial intentions. Understanding of the effects of entrepreneurship education would allow educators to design better courses. Such an understanding is lacking for the effects of education more generally: Oreopoulos and Salvanes (2011) argue that the non-pecuniary effects of education have been neglected in economics ${ }^{1}$ while Gage (2009) notes that effects of course content are widely neglected in education research. Although the literature on entrepreneurship education does address the effects of different kinds of content (Souitaris et al., 2007; Fitzsimmons and Douglas, 2010) it does not use consistent terminology or methodology and has produced conflicting results.

This study distinguishes two kinds of content provided in entrepreneurship courses: vocational content and content that forms entrepreneurial skills ${ }^{2}$. The effects of both types of content are identified empirically using non parametric tests as well as a structural equation model. It is shown that both contribute to the formation of entrepreneurial intentions and also that they are weak complements. This last finding contrasts with the results of Fitzsimmons and Douglas (2010). We reconcile this apparent conflict as well as the conflicting evidence on average entrepreneurial intentions by drawing on the distinction between vocational and skill directed content as well as evidence on sorting of students resulting from entrepreneurship education.

The main contribution of this paper lies in empirical evidence showing that entrepreneurship education increases perceived entrepreneurship skills (e.g. business plan writing) and also helps in the discovery and appraisal of entrepreneurship as a vocation. We show that these two effects may conflict for students who do not perceive entrepreneurship to be desirable: better skills make students more confident, raising intentions. At the same time a significant proportion of students will recognize that they do not perceive entrepreneurship to be desirable creating a countervailing effect.

Should this conflict of effects be reflected in the design of entrepreneurship courses? For instance entry level courses could focus only on desirability by emphasizing experiences of entrepreneurs as suggested by Souitaris

For rare exceptions refer to Brown and Corcoran (1997) and Allgood et al. (2010) who provide evidence that course content affects both pecuniary and non-pecuniary outcomes of education. Additionally, Akerlof and Kranton (2002) and Bishop (2006) study participation decisions and the process of identity formation in education.

2 A similar dichotomy of content may apply in many educational settings although it is likely that the vocational element of entrepreneurship education is particularly pronounced. 
et al. (2007). This would promote sorting of students as we demonstrate below. However, we show that entrepreneurship skills are a weak complement to vocational course elements. This suggests that a very strong focus on vocational elements would reduce the effectiveness of entrepreneurship courses even if the only aim were to sort real entrepreneurs from all other students.

To show this we draw on the Theory of Planned Behavior (TPB) (Ajzen, 1991; Fishbein and Ajzen, 2010). It identifies three distinct attitudinal factors that affect a person's intentions: perceptions of the desirability of an action for that person, of the social norms regarding that action and of the degree of behavioral control the person has in undertaking the action. Each of these attitudes may change in response to content taught in entrepreneurship courses. Perceptions of behavioral control are affected by content focusing on the skills needed by an entrepreneur ${ }^{3}$. Perceptions of the desirability of entrepreneurship and social norms surrounding it will respond more to content dealing with the practice and experiences of actual entrepreneurs, often referred to as "war stories"

To identify how the two aspects of entrepreneurship education affect intentions we apply a structural equation model to the TPB. The literature on the TPB provides a well grounded set of items with which we are able to measure the attitudinal factors posited by the theory. Responses to these items were elicited in two surveys before and after a mandatory entrepreneurship course at the undergraduate level. By applying a structural equation model we can separately identify the effects of each latent attitudinal factor posited by the TPB on entrepreneurial intentions. Additionally, we provide evidence from non parametric tests that the attitudinal factors we measure identify skills and vocational attitudes separately.

We estimate the structural model using an instrumental variables estimator as suggested by Bollen (1996). In contrast to the usual full information maximum likelihood estimators applied to structural equation models Bollen's estimation approach is more robust to misspecification of the structural model.

\section{Theory}

Entrepreneurship is often analyzed as a form of intentionally planned behavior (Shapero and Sokol, 1982; Bird, 1988). In this literature, intentions-based models from social psychology are employed in entrepreneurship research to predict entrepreneurial activity. These models also provide a promising framework for the evaluation of entrepreneurship education. In this section we discuss the Theory of Planned Behavior (Ajzen, 1985, 1991; Fishbein and Ajzen, 2010) and its application to studying effects of different kinds of content in entrepreneurship courses.

Entrepreneurship as Intentionally Planned Behavior Research in social psychology shows that intentions are the single best predictor of every planned behavior, even when this behavior is rare, hard to observe or observed with a significant time lag (Bagozzi and Yi, 1989; Ajzen, 1991). According to Bird (1988) (p. 442), "intentionality is a state of mind directing a person's attention (and therefore experience and action) toward a specific object (goal) or path in order to achieve something (means)".

\footnotetext{
We provide evidence that the perception of behavioral control and skills are correlated in the appendix to this paper. This may fall partly into the domain of meta-cognitive knowledge as defined by Anderson and Krathwohl (2001). However, it seems more fitting to state that the course schools students' "interpersonal intelligences" (Gardner, 1983), i.e. their ability to understand others' desires, intentions and motivations.
} 
Intentions predict actual behavior, while specific attitudes influence intentions. In turn individuals' attitudes arise from "exogenous influences" (Ajzen, 1987), such as personality traits, demographic and situational variables (Ajzen, 1991) or role models (Scherer et al., 1989). The attitude-intention model integrates the trait approach (Brockhaus, 1980) and provides an explanation for its unsatisfying results (Gartner, 1988; Robinson et al., 1991; Krueger et al., 2000): traits influence intentions (or behavior) only indirectly through the specific attitudes, either by strengthening or weakening the focal individual's attitudes. Both intentions and attitudes are based on individual perceptions, which may be influenced (Ajzen, 1991). That is why intentions vary among individuals (Krueger et al., 2000). So behavioral or intentions-based approaches describe how exogenous influences affect individual attitudes, and indirectly intentions, potentially altering actual behavior (Fishbein and Ajzen, 2010).

Intentions based models are sometimes criticised because it is argued that intentions do not necessarily carry over into actions. This may be especially true of the choice of a vocation such as becoming an entrepreneur which may only be realized many years after university education is completed.

This critique can be countered in two ways. First, there is an extensive literature in which the TPB is applied to a very diverse range of intentions based behaviors. These empirical tests show that the theory is quite robust and that intentions are reliable predictors of people's actions. Montaño and Kasprzyk (2008) and Fishbein and Ajzen (2010) review some of this work. Second, in Appendix 7.1 we test whether the intentions reported by students taking part in our survey are reflected in their success in a business plan competition which took place subsequent to the surveys we analyze. We find that entrepreneurial intentions are a significant predictor of success in this competition. This shows that entrepreneurial intentions elicited by our survey have measurable effects on students' entrepreneurial activity at least in the short run.

The Theory of Planned Behavior The social psychology literature on intentions is dominated by models derived from the TPB (Ajzen, 1985, 1991; Fishbein and Ajzen, 2010). According to the TPB, the intention to perform a behavior derives from three attitudinal factors: perceived desirability, perceived social norms and perceived behavioral control.

Perceived desirability ${ }^{5}$ derives from the individual's positive or negative evaluation of the outcome when exercising the behavior in question. It depends on information-based convictions, i.e. the probability of a positive or negative consequence of the execution of the behavior. Regarding entrepreneurship, this factor reflects the difference in the (after consideration of the available information) evaluations of being self-employed or organizationally employed.

Perceived social norms mirrors the perceived social pressure to perform the behavior in question or not. It depends on the normative convictions regarding the expectations of the focal individual's important persons and her motive to comply with them. Regarding entrepreneurship, this factor indicates the perceived pressure from other people to enter an entrepreneurial career or not.

Perceived behavioral control reflects the subjective perception of the ability to perform the behavior in question. It depends on the total set of accessible control beliefs, i.e., beliefs about the presence of factors that may facilitate or impede performance of the behavior. This factor overlaps with Bandura's "perceived self-efficacy" (Bandura, 1977).

The TPB has been used to predict entrepreneurial behavior (Kolvereid, 1996a; Krueger et al., 2000; Kolvereid In the literature, this factor is also often called "Attitude towards behavior" 
and Isaksen, 2006). Recently the theory has been employed in evaluations of entrepreneurship education (Fayolle et al., 2006; Souitaris et al., 2007). Building on the TPB Souitaris et al. (2007) distinguish effects of entrepreneurship education on learning, inspiration and resource-utilisation. Using a pretest-post-test quasi-experiment they find support only for the effect of inspiration on norms and on intentions ${ }^{6}$. A similar methodology is employed by Fitzsimmons and Douglas (2010) who distinguish between perceived feasibility and perceived desirability leaving social norms aside.

In contrast to this methodology Liñán (2008) estimates a structural equation model of the TPB using Partial Least Squares. His results indicate that all three attitudinal factors posited by the TPB affect entrepreneurial intentions. Perceived behavioral control emerges as a stronger influence on intentions than perceived desirability. A direct effect of perceived social norms on intentions is not tested.

These papers all make a distinction between the skill (learning or perceived feasibility) component of entrepreneurship education and the vocational components (inspiration or perceived desirability). Only one paper (Liñán, 2008) also studies the effect of social norms on entrepreneurial intentions. Two empirical contradictions emerge from these studies: first, Souitaris et al. (2007) show that entrepreneurial intentions increased on average as a result of entrepreneurship education, contrasting with the results of Oosterbeek et al. (2010) and von Graevenitz et al. (2010). Second, Fitzsimmons and Douglas (2010) allow for the interaction of vocational and skill directed course content in determining students' intentions. They find the two types of content to be substitutes, a result which we cannot replicate.

In this paper we make explicit the distinction between the effect of entrepreneurship education on students' skills and the effects of such education on their choice of vocation. Appendix 7.1 shows that changes in students' skills can be measured through changes in the attitudinal factor perceived behavioral control. There it is also shown that the remaining two attitudinal factors are strongly correlated with each other. In the appendix this is demonstrated using simple correlation of scales measuring these attitudinal factors. In Section 5.1 we provide further evidence for the strong links between perceived desirability and perceived social norms. This evidence is derived from the estimation of a structural equation model. Both types of evidence show that the two effects of entrepreneurship education can be identified separately.

In Section 4.4 we demonstrate that students' perceptions of their skills improve significantly as a result of the course. In contrast, we find that their perceptions of the desirability of entrepreneurship increase less strongly and that the variance in their perceptions of the desirability of entrepreneurship increases. Finally, in Section 5.2 we demonstrate that both effects of entrepreneurship education increase students' entrepreneurial intentions. Section 5.3 provides further evidence that the effects are complements.

In the conclusion 6 we discuss how these findings allow us to reconcile the conflicting results in the literature that we note above.

\section{A Structural Equation Model of Planned Behavior}

In this section we develop a structural equation model which encompasses the TPB and discuss how this model can be estimated. In Section 5 we apply this model to our survey data. The results discussed there provide the core of our evidence supporting the claim that entrepreneurship education has separate and identifiable effects on skills

The vocational course contents have strongest effects on intentions in this study too. 
and students' vocational attitudes.

The three attitudinal factors that determine intentions in the TPB are latent variables, that is they are not directly observable or measurable. Below we use sets of items derived from previous literature ( discussed in Section 4.3) to measure these latent variables. In this section we show how these items can be used to construct a structural equation model and how this can be estimated using two stage least squares. This section also discusses assumptions underlying the structural equation model and its identification.

Deriving the Structural Equation Model The TPB provides this latent variable model:

$$
\triangle \eta=\alpha_{L}+\gamma_{C} \triangle \xi_{C}+\gamma_{N} \triangle \xi_{N}+\gamma_{D} \triangle \xi_{D}+\zeta
$$

The latent dependent variable $\triangle \eta$ is the change in entrepreneurial intention which is brought about by an entrepreneurship course. Intention is a function of three latent exogenous variables: perceived behavioral control $\left(\xi_{C}\right)$, perceived social norms $\left(\xi_{N}\right)$ and perceived desirability $\left(\xi_{D}\right)$. Accordingly, the change in intention is a function of changes in the three attitudinal factors as set out in Equation (1). Here $\zeta$ is a random disturbance with $E(\zeta)=0$ and $\operatorname{Cov}\left(\zeta \zeta^{\prime}\right)=0$. Equation (1) presents a standard latent variable model for a structural equation model (Bollen, 1996).

If the latent exogenous variables and the latent outcome were observable we would estimate equation (1) directly. Since neither the variables nor the outcome are observable we resort to using items to measure the latent variables and the outcome. In the case of the latent exogenous variables we have multiple (at least four) items and we test validity and reliability of the latent constructs in Section 4.3. We measure the dependent variable with one item. $^{7}$

All items are derived from previous studies and documented in Section 4.3. The relationships between these items and the latent variables are summarized in the measurement model below. The measurement model consists of the following measurement equations:

$$
\begin{array}{ll}
\triangle x_{1 C}= & \triangle \xi_{C}+\boldsymbol{\kappa}_{1 C}^{\prime} \boldsymbol{C}_{1 C}+\delta_{1 C} \\
\triangle x_{1 N}= & \triangle \xi_{N}+\boldsymbol{\kappa}_{1 N}^{\prime} \boldsymbol{C}_{1 N}+\delta_{1 N} \\
\triangle x_{1 D}= & \triangle \xi_{D}+\boldsymbol{\kappa}_{1 D}^{\prime} \boldsymbol{C}_{1 D}+\delta_{1 D} \\
\triangle x_{2 C}=\tau_{2 C}+\lambda_{2 C} \triangle \xi_{C}+\boldsymbol{\kappa}_{2 C}^{\prime} \boldsymbol{C}_{2 C}+\delta_{2 C} \\
\triangle x_{2 N}=\tau_{2 N}+\lambda_{2 N} \triangle \xi_{N}+\boldsymbol{\kappa}_{2 N}^{\prime} \boldsymbol{C}_{2 N}+\delta_{2 N} \\
\triangle x_{2 D}=\tau_{2 D}+\lambda_{2 D} \triangle \xi_{D}+\boldsymbol{\kappa}_{2 D}^{\prime} \boldsymbol{C}_{2 D}+\delta_{2 D} \\
\vdots & \\
\triangle y & =
\end{array}
$$

This measurement model codifies the assumption that the students' levels of each of the three exogenous latent variables determine their responses to the items in the survey and thus the levels of the indicator variables $\left(x_{k K}\right)$ where $k \in\{1,2,3,4,5\}$ and $K \in\{C, N, D\}$. This means that the latent exogenous variables are reflective

This requires us to set the effect of the change in entrepreneurial intention $(\Delta \eta)$ on the item measuring it $(\Delta y)$ to one as reflected in equation (2) below. 
constructs which determine the indicator variables $\left(x_{k K}\right)$ (Bollen et al., 2008). The first set of these measurement equations is used to scale the latent variables as proposed by Bollen (1996). We augment the measurement model by introducing the possibility that responses to each item are also affected by control variables $\left(\boldsymbol{C}_{k K}\right)$ such as measures of personality and peer effects. The measurement model also clarifies our assumption that the item measuring entrepreneurial intention - the effect indicator $y$-is determined by the level of the latent entrepreneurial intention as well as a vector of control variables $(\boldsymbol{W})$. This contains the Big Five personality domains, students' gender and prior interest in entrepreneurship.

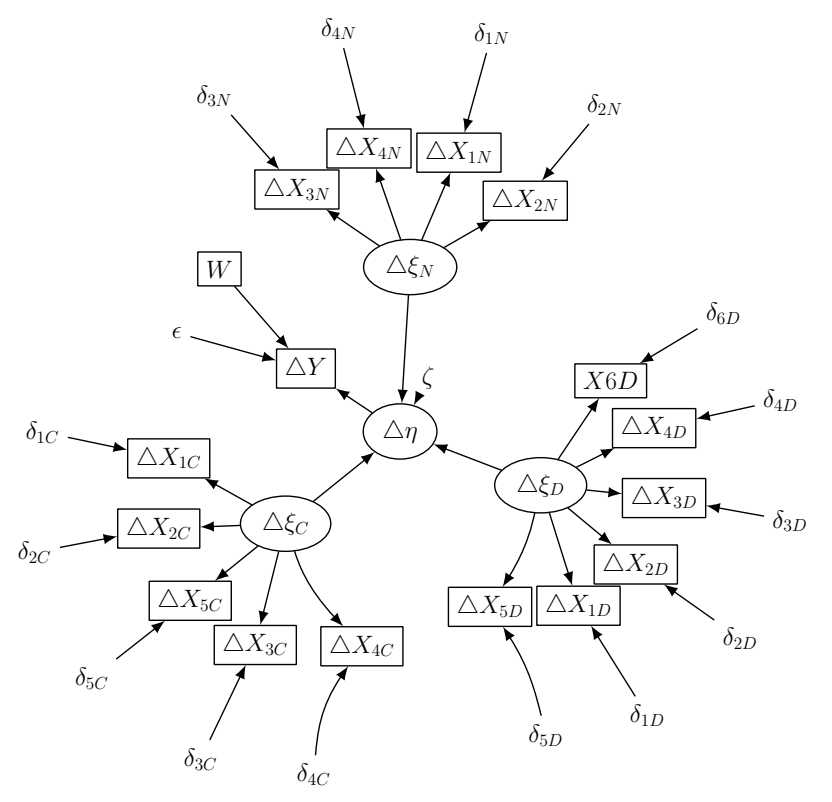

Figure 1: Path Diagram of the Idealized Structural Equation Model

Note: This figure shows the first differenced structural equation model presented in this section. Variables presented in circles are latent variables: $\eta$ - entrepreneurial intention and $\xi_{D}$ perceived desirability, $\xi_{N}$ perceived social norms, $\xi_{C}$ perceived behavioral control. Variables in squares are observed items, e.g. $X_{10}$ or exogenous variables, e.g. $W$. All remaining variables are i.i.d. error terms, e.g. $\epsilon$ or $\delta_{1}$. We exclude control variables for the measurement model in order not to clutter the graph.

The structural model discussed here can be represented in a path diagram. In Figure 1 we set out the causal relationships (arrows) between effect variables, latent variables and items. The figure depicts causal relationships between latent variables (depicted in round circles) as well as relationships between these latent variables and the measurable items (depicted in squares) that reflect these latent variables. Recent work by Pearl $(1995,2009,2012)$ shows that a causal interpretation of structural equation models is warranted. The usefulness of graphical analysis in clearly setting out causal effects is also emphasized by Chalak and White (2011) and White and Lu (2011).

Figure 1 shows that each measurement of a latent variable by an item is affected by statistical errors $\left(\delta_{k K}\right)$ which are assumed to be independent of one another. Below we discuss this assumption of independence as it is key for identification of the model.

It is important to note that this path diagram and the measurement model present an idealized version of the TPB. It is quite likely that some of the items included in the survey reflect more than one of the latent variables. In the path diagram this would mean that arrows are missing which connect the latent variables to those additional items that also reflect them. We allow for this possibility when estimating the measurement model but abstract from it in Figure 1 above. 
Estimating the Latent Variable Model By inverting the scaling equations from the measurement model and replacing the latent variables with their analogs we can rewrite the latent variable model as follows (Bollen, 1996; Kirby and Bollen, 2009; Bollen et al., 2008):

$$
\triangle y=\alpha_{L}+\sum_{K \in\{C, N, D\}} \gamma_{K}\left(\triangle x_{1 K}-\boldsymbol{\kappa}_{1 K}^{\prime} \boldsymbol{C}_{1 K}\right)+\boldsymbol{\kappa}_{L}^{\prime} \boldsymbol{W}+\zeta+\epsilon-\sum_{K \in\{C, N, D\}} \gamma_{K} \delta_{1 K}
$$

This equation cannot be estimated by OLS as the scaling items $\left(x_{1 K}\right)$ are correlated with the error terms if the scaling items are measured with error (Bollen, 1996). To estimate the model by 2SLS we have to find suitable instruments for the endogenous indicator variables. Bollen (1996) argues that we may use the remaining indicator variables for each latent variable from the measurement model as instruments if their error terms are not correlated with $\delta_{1 K}$. These variables are referred to as the "model implied instrumental variables".

The independence of the errors $\delta_{k K}$ within each set of items $K$ is the assumption allowing us to identify the effects of the latent variables on entrepreneurial intention. If this assumption is violated and some of the error terms are not independent, then some of the "model implied instruments" will not be admissible as instruments. It is important to note that we are concerned only with correlation of the errors within each set of items associated with one particular exogenous latent variable. Only the items measuring the same latent variable can be used as instruments, as only these reflect the same latent variable as the item being instrumented.

The assumption of independence applied to the errors $\delta_{k K}$ within each set of items $K$ implies that we assume that each set of items measures only the latent variable it is intended to measure and no further unobserved factors that might affect answers to one or more subsets of these items. In Section 4.3 we analyze the correlation structure of the items used in this study. Analysis of the reliability of the items used to measure each exogenous latent variable shows that each set of items loads on the same factor and that each item loads significantly on this factor. Furthermore, we undertake a factor analysis of these sets of items to uncover additional unobserved factors loading onto subsets of them. We find that the scaling item (item 1) for perceived desirability is correlated with such a common factor affecting item 4 measuring perceived desirability. ${ }^{8}$ In all other cases we do not uncover such common factors between the scaling items and other items. We have also not found any evidence that there are common factors affecting items loading onto separate latent attitudinal factors. This provides us with some confidence in the independence assumption. Figure 4 provided in the appendix illustrates the correlations with the common latent factors as well as other factors.

Estimating the Measurement Model The structural equation model including the measurement model can be estimated by maximum likelihood methods such as those implemented in LISREL. However, this approach to estimation imposes strong regularity conditions and this implies that misspecification in one part of the model may affect all estimation results (Bollen et al., 2007; Kirby and Bollen, 2009). As Bollen (1996) notes the non-iterative 2SLS estimator is more robust and computationally less intensive than the full-information alternatives. We adopt this estimator because it also provides more flexibility in specifying individual equations within the measurement model. In particular, it allows us to individually select the instrument sets we employ for each equation that is estimated. Starting from the full set of model implied instrumental variables we dropped those instruments that

$8 \quad$ We exclude item 4 measuring perceived desirability from the set of model implied instruments. This does not significantly affect our findings below. 
were only weakly correlated with the endogenous scaling items. By doing this we were able to reduce the potential for bias resulting from weak instruments (Stock and Yogo, 2002; Baum et al., 2007).

Alternatively, it would also be possible to estimate the equations of the measurement model jointly as a system of equations using GMM. We do not implement this method of estimating the model as it would require that we employ the same set of instruments for each of the equations in the measurement model. This would reintroduce the potential for weak instruments bias.

Just as above we substitute out the latent variables in the measurement model equations with the help of the scaling equations. This induces endogeneity so that once more we apply the 2SLS estimator. The instruments we use are the same as above:

$$
\triangle x_{m K}=\tau_{m K}+\sum_{K \in\{C, N, D\}} \lambda_{1 K} \triangle x_{1 K}-\boldsymbol{\kappa}_{1 K}^{\prime} \boldsymbol{C}_{1 K}+\delta_{m K}-\sum_{K \in\{C, N, D\}} \lambda_{1 K} \delta_{1 K}
$$

where $m \in\{2,3,4,5\}$ and $K \in\{C, N, D\}$.

Notice that here we have augmented the measurement model to reflect the possibility that each item in our survey reflects not just one but all three of the latent variables posited by the Theory of Planned Behavior. If the theory is well specified we would expect the coefficients on the scaling items measuring the same latent variable as the dependent item to be significant and positive. If further coefficients are significant, then this indicates that the items reflect more than one latent variable. This is possible under the Theory of Planned Behavior (Fishbein and Ajzen, 2010). However, we would argue that the distinction between the latent variables will be lost if all of the remaining coefficients were to be significant. Shah and Goldstein (2006) refer to this as "double loading" in their review of structural equation modeling and indicate it is to be avoided. This is essentially an identification issue at the level of the measurement model. In the case of the Theory of Planned Behavior double loading is not excluded by the theory. Identification rules for the measurement model which do not necessarily exclude double loading are discussed by Bollen and Davis (2009). We discuss and apply these further below.

\section{Data Description and Nonparametric Tests}

This section describes the setting in which our surveys were administered and provides a first set of tests. These tests validate the survey instrument and provide nonparametric evidence on changes in students' perceptions resulting from the course we study. We address two questions with these tests: firstly, do the items employed identify the latent constructs posited by the TPB and secondly, are the latent constructs affected in different ways by the course?

\subsection{Setting for the Survey}

The students we surveyed about their entrepreneurial intentions are drawn from the business administration bachelor degree offered by the Munich School of Management at the Ludwig-Maximilians-Universität Munich. In their $3^{\text {rd }}$ semester students on this degree take a mandatory course on "Business Planning". As the course takes place early in the degree and is mandatory, students' answers are not affected by previous courses or any selection bias in the set of business school students.

The course "Business Planning" is organized as follows: Every year, the 3rd semester students take the course 
in the winter term. The students attend lectures in which they are taught basic principles of entrepreneurship and the writing of business plans. Additionally, guest speakers such as entrepreneurs, marketing or finance experts provide practical input. Parallel to the lectures students work together in randomly assembled teams of four to six in order to develop a business plan (team-members of one focal student are called "peers" in the following). Each of the teams cooperates with a Munich-based entrepreneur who provides his or her business idea for the business planning task. This allows the students to leave the purely academic setting and to gain insight into the day to day activities of an entrepreneur. Finally, four teams at a time attend a weekly meeting led by Munich School of Management faculty. In these meetings the teams present their business planning progress and receive feedback.

At the end of the course student teams have to submit a complete business plan and present it to faculty and entrepreneurs. Grades are based on team performance in the written business plan and presentation as well as on individual achievement (each team-member is "responsible" for one chapter of the business plan). There is also an independently assessed award for the ten best business plans.

On average every year approximately 400 students attend "Business Planning", grouped into 80 teams with four to six students each, cooperating with 40 entrepreneurs.

\subsection{Data Collection}

The data analyzed below were collected in two surveys during the winter semesters 2008-09 (cohort 1) and 2009-10 (cohort 2). To measure changes in attitudes and intentions resulting from the Business Planning course a pre-test post-test design was adopted. Both cohorts filled out online-questionnaires directly before the first session (ex-ante questionnaire) of the course and directly after they submitted their final business plan, but before the grades were communicated (ex-post questionnaire). As the students made their statements anonymously, the matching of exante and es-post questionnaires was achieved through a structured identification code. ${ }^{9}$ All students were told that the surveys were being undertaken for research purposes only, that their participation in the survey was voluntary and that their information would not affect their grades. The questionnaires were reviewed by 3 academics and 5 non-participating students to ensure clarity of wording and validity of the constructs. ${ }^{10}$

409 students were enrolled in the course in cohort 1 and 405 students in cohort 2. A total of 622 students answered the ex ante questionnaire (280 students in cohort 1, 342 in cohort 2 respectively), and a total of 566 students filled in the ex post questionnaire (276 and 290 students respectively). We achieved a matching of questionnaires for 199 students of cohort 1 and 279 students of cohort 2.

For the multivariate analysis below, we had to drop some observations due to additional missing information. For students from cohort 1 we experienced some difficulties in identifying the teams that students had worked in. As we employ several peer-effects variables, we had to drop 43 observations from this cohort. Furthermore, due to missing values in single items, we drop a further eight observations from cohort 1 and 22 observations from cohort 2. This leaves us with a total of 405 valid observations, i.e. complete and matched questionnaires. When not indicated otherwise, the following analysis is based on these observations. In Appendix 7.2 we provide evidence that restricting the sample in this manner does not lead to non-response bias in the dependent variable.

\footnotetext{
$9 \quad$ The code consisted of the first letter of the first name of the student's mother, the last letter of the student's name, the first digit of the student's month of birth, and the first letter of the student's place of birth.

10 Translated questionnaires are available from the authors upon request.
} 


\subsection{Measures and Descriptive Statistics}

Here we discuss the variables obtained from the surveys. The items used and the variables constructed are derived from existing theoretical and empirical work on the TPB as applied to entrepreneurship. Details are provided in each subsection.

Additionally, this section provides psychometric properties of the items measuring latent variables. Following Chandler and Lyon (2001) and Liñán and Chen (2009), the psychometric properties are tested in two steps: first we investigate validity of the scales and then we analyze their reliability.

Validity analysis We carefully considered structural and content validity in the development of the instrument, and ensured that the items used are both relevant and representative of the latent attitudinal factors being measured. Next we used confirmatory factor analysis to assess convergent validity. All items loaded on the expected factor only, however two anomalies appeared. The Perceived Behavioral Control item 4 in the ex-ante data and the Perceived Behavioral Control items 4 and 6 in the ex-post data did not load on any of the three attitudinal factors with a loading above 0.4. The differences in items 4 and 6 measuring Perceived Behavioral Control do not load on the difference in Perceived Behavioral Control. Therefore, we exclude these two items when building both the ex-ante and ex-post measure of Perceived Behavioral Control ${ }^{11}$. We assessed discriminant validity by looking at correlations. Correlations of each item to other constructs were always below the correlations with their own construct as required.

\section{Table 1: Construct Reliability}

\begin{tabular}{|c|c|c|c|c|c|c|c|}
\hline Variable & Statistic & Ex-ante & s.e. & Ex-post & s.e. & Difference & p-value \\
\hline Entrepreneurial intention & mean & 4.19 & 0.089 & 3.91 & 0.092 & 0.281 & $0.000^{* * *}$ \\
\hline \multirow[t]{3}{*}{ Perceived desirability } & mean & 4.29 & 0.072 & 4.35 & 0.076 & 0.065 & 0.138 \\
\hline & $\alpha$ & 0.89 & & 0.92 & & 0.81 & \\
\hline & $\omega_{h}$ & 0.87 & & 0.87 & & 0.77 & \\
\hline \multirow[t]{3}{*}{ Perceived social norms } & mean & -4.68 & 1.46 & -1.13 & 1.54 & 3.553 & $0.002^{* *}$ \\
\hline & $\alpha$ & 0.93 & & 0.94 & & 0.85 & \\
\hline & $\omega_{h}$ & 0.92 & & 0.92 & & 0.83 & \\
\hline \multirow{3}{*}{$\begin{array}{l}\text { Perceived behavioral } \\
\text { control }\end{array}$} & mean & 4.22 & 0.044 & 4.32 & 0.046 & 0.102 & $0.003^{* *}$ \\
\hline & $\alpha$ & 0.79 & & 0.79 & & $0.50(0.70)$ & \\
\hline & $\omega_{h}$ & 0.57 & & 0.75 & & $0.60(0.69)$ & \\
\hline
\end{tabular}

Note: This table provides differences of mean tests, as well as tests of the reliability of latent constructs. These latter tests are Cronbach's $\alpha$ as well as McDonald's $\omega_{H}$.

Construct Reliability Table 1 above provides a number of descriptive statistics and tests for the latent variables in our structural equation model. Among others the table presents tests of construct reliability where a latent variable is based on three or more items. These tests show whether the items grouped together as reflective measures of each latent variable are correctly grouped together. We estimate two measures of construct reliability: Cronbach's $\alpha$ and McDonald's $\omega_{H}$.

11 In results not reported in the paper but available from the authors we also estimated the measurement model including these items. We found the items did not reflect any of the three attitudinal factors posited by the Theory of Planned Behavior. 
Cronbach's $\alpha$ is widely used in the literature to evaluate construct validity; values in excess of 0.7 are regarded as indicating high reliability of the construct (Nunnally, 1978). However Zinbarg et al. (2005) and Revelle and Zinbarg (2009) argue that Cronbach's $\alpha$ may reflect latent group factors that jointly determine subsets of the items included in a scale. In this case there need not even be a common latent factor. Therefore we also estimate McDonald's $\omega_{H}$ which provides an accurate measure of the proportion of variance in the items which is due to a unique common factor (Revelle and Zinbarg, 2009). The loading of the items onto that common factor as well as the loadings on additional latent factors is further illustrated in Figure 4 in the appendix.

In general Table 1 provides support for the items we employ as measures of the latent attitudinal factors. We discuss details of our results in the following sections.

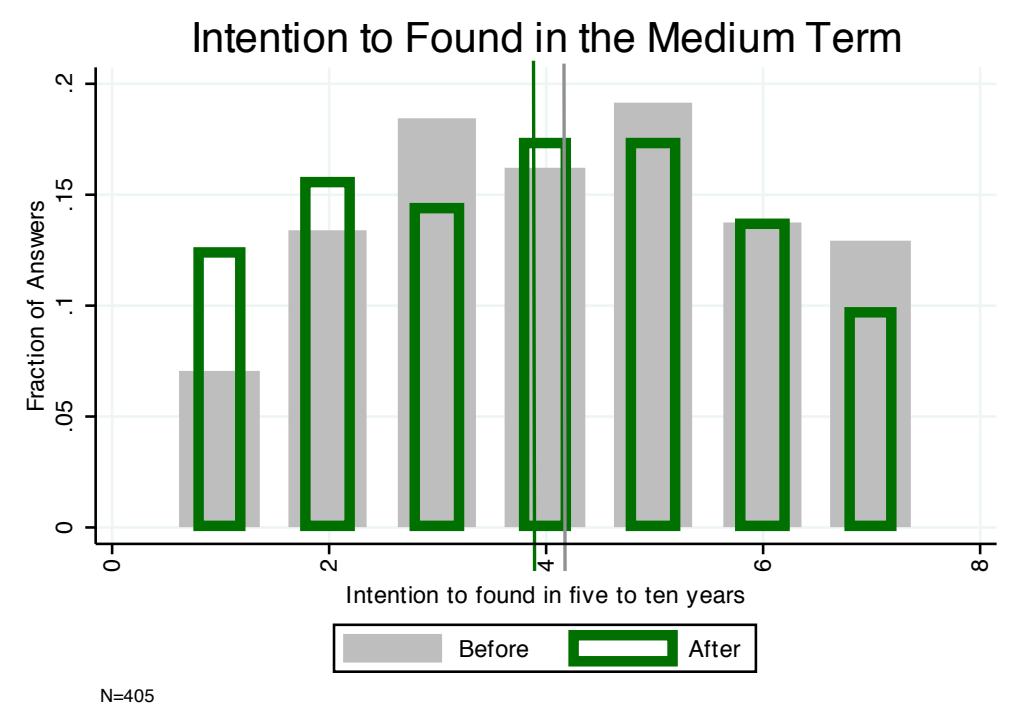

Figure 2: Measures of intention before and after the course.

Entrepreneurial Intention This variable is the dependent variable in the latent variable model. It reflects the student's latent intention to pursue an entrepreneurial venture. We measure this using a single item proposed by Shapero and Sokol (1982). Students were presented with the statement "I intend to start my own business in the next ten years" and asked to indicate their agreement to it on a seven-point Likert-scale with answers ranging from "completely disagree" to "completely agree".

Figure 2 provides information on the mean of students' responses to the item (horizontal lines) and the distribution of their responses ex ante and ex post. Clearly mean entrepreneurial intention decreased. In Table 1 above we show that this decrease is statistically significant at the $1 \%$ percent level. Table 3 in Section 4.4 shows that the standard deviation of students' entrepreneurial intentions increases as a result of the course. This indicates that students are being sorted into two groups by the course.

Perceived Desirability, Perceived Behavioral Control and Perceived Social Norms Next we discuss measurement of the three latent constructs that jointly determine entrepreneurial intentions according to the Theory of Planned Behavior. 
Perceived Desirability Perceived desirability is measured using a five-item measure on a seven-point Likertscale first developed by Gundry and Welsch (2001) and subsequently adopted by Kolvereid and Isaksen (2006). Students indicated their agreement to the following statements (1 "completely disagree" - 7 "completely agree").

1. I would rather own my own business than earn a higher salary as an employee.

2. I would rather own my own business than pursue a promising career as an employee.

3. I am willing to make significant personal sacrifices in order to stay in my own business.

4. I would work somewhere else only in order to make another attempt to start my own business.

5. I am willing to work more with the same salary in my own business, than as an employee.

To test whether the items jointly measure an underlying construct Table 1 provides two test statistics, Cronbach's $\alpha$ and McDonald's $\omega_{H}$. Both statistics indicate that the ex ante and ex post items and their differences measure an underlying construct as their values are very similar and well above 0.7 . Table 1 also shows that the mean value of the construct is not significantly shifted by the course. In contrast, Table 4 below provides some evidence of a rightward shift of students' perceptions of desirability. More importantly, Table 3 below shows that the variance of students' perceptions of the desirability of entrepreneurship increased significantly. This suggests that the course induces more polarized views of perceived desirability of entrepreneurship in the students taking it.

Perceived Social Norms To measure perceived social norms three-items (7-point Likert-scales) are adopted from Kolvereid (1996b). These were subsequently used by Tkachev and Kolvereid (1999), Kolvereid and Isaksen (2006), and Souitaris et al. (2007). The items assess whether family members, friends or other important persons thought that the respondent ought to become an entrepreneur or not. We include an additional item about the opinions of fellow students, as this perception becomes important in entrepreneurship courses in which students receive repeated feedback from their peers.

We asked students to indicate their agreement to the respective statements (1 "completely disagree" - 7 "completely agree"). The four items were transformed to yield a symmetric scale from -3 to 3 , which was then multiplied by a weight indicating to which extent the respondent cares about the expectation of the respective group (four items on 7-point Likert scales). This yields a symmetric scale running from -21 to 21 .

1. My closest family think that I should start my own business.

2. My closest friends think that I should start my own business.

3. My fellow students think that I should start my own business.

4. Other people who are important to me think that I should start my own business.

5. For me, the expectations of my closest family are (not important at all - very important).

6. For me, the expectations of my closest friends are (not important at all - very important).

7. For me, the expectations of my fellow students are (not important at all - very important).

8. For me, the expectations of other people, who are important for me, are (not important at all - very important).

Cronbach's $\alpha$ and McDonald's $\omega_{H}$ (cf. Table 1 ) indicate that the ex ante and ex post items, their differences and the squared differences of these measure an underlying construct as the statistics are very similar and well above 0.7. The table also shows that the difference in means for this measure is significantly positive. This indicates that the course led students to evaluate social norms more positively. The tests reported in Table 4 do not provide much 
support for this shift however. Table 3 shows that we also have no evidence that perceptions of social norms became significantly more polarized. Overall perceptions of social norms towards entrepreneurship seem not to have been affected by the course.

Perceived Behavioral Control A measure of perceived behavioral control was obtained from a scale of six items on 7-point Likert-scales suggested by Kolvereid (1996a). This measure has subsequently been used by Tkachev and Kolvereid (1999) and Souitaris et al. (2007). Again, we asked students to indicate in how far they agreed to the following statements (1"completely disagree" - 7"completely agree").

1. For me, being self-employed would be very easy.

2. If I wanted to, I could easily pursue a career being self-employed.

3. Being self-employed, I would have complete control over the situation.

4. The number of events outside my control which could prevent me from being self-employed is very high.

5. If I become self-employed, the chances of success would be very high.

6. If I pursue a career being self-employed, the chances of failure would be very high.

Note: Items 4 and 6 are reverse-coded.

To test whether these items jointly measure an underlying construct Table 1 provides Cronbach's $\alpha$ and McDonald's $\omega_{H}$. In this case McDonald's $\omega_{H}$ indicates that the construct is not as reliable as one would like ex ante. More specifically McDonald's $\omega_{H}$ indicates that the high value of Cronbach's $\alpha$ reflects strong group factors relative to the general factor we are interested in measuring (Zinbarg et al., 2005). We have found that this is due to items 4 and 6 , and is perhaps due to reverse-coding. In case of the difference between ex ante and ex post items we also report the statistics when we exclude items 4 and 6 in brackets. Once this is done the construct can be seen to be just at the level of reliability which the literature regards as adequate (0.7).

Table 1 also shows that the mean value of this construct increases. This indicates that the course improves the average students' impression of being able to undertake entrepreneurial tasks. The upward shift in students' perceptions of behavioral control is confirmed by the tests set out in Table 4 below. In contrast, there is no evidence of a simultaneous polarization of students' perceptions on the basis of the tests set out in Table 3 below.

Description of Exogenous Variables Now we discuss control variables included in the two surveys. Descriptive statistics for these variables are provided in Table 2 below.

Big 5 personality domains To obtain measures for the Big 5 personality domains extraversion, agreeableness, conscientiousness, emotional stability, and openness to experiences we employed the Ten-Item Personality Inventory (7-point Likert scales) developed by Gosling et al. (2003).

Prior exposure to entrepreneurship To obtain a measure of prior exposure to entrepreneurship we included four items asking for four possible types of entrepreneurial experience following Krueger (1993). We asked the following four questions (coded 1 for yes, 0 for no):

Did your parents ever start a business? Did they ever work for a small or new company? Did you ever start a company on your own? Finally we asked for an estimate of the number of acquaintances that have started a business. In one case a student provided a very high estimate which we found had an effect on the significance of this variable in several regressions. We reduced the variable to the $99^{\text {th }}$ percentile in this case. This change did not affect the significance or interpretation of any of the main variables of interest. Table 2 reflects this change. 
Table 2: Determinants of Perceived Desirability, Perceived Social Norms and Perceived Behavioral Control

\begin{tabular}{|c|c|c|c|c|c|}
\hline Variable & Mean & SD & Median & Min & Max \\
\hline Ex-ante intention to become an entrepreneur & 4.190 & 1.789 & 4 & 1 & 7 \\
\hline Ex-ante perceived desirability - item 1 & 3.807 & 1.801 & 4 & 1 & 7 \\
\hline Ex-ante perceived desirability - item 2 & 4.422 & 1.741 & 4 & 1 & 7 \\
\hline Ex-ante perceived desirability - item 3 & 4.025 & 1.66 & 4 & 1 & 7 \\
\hline Ex-ante perceived desirability - item 4 & 4.24 & 1.745 & 4 & 1 & 7 \\
\hline Ex-ante perceived desirability - item 5 & 4.948 & 1.71 & 5 & 1 & 7 \\
\hline Ex-ante perceived social norms - weighted item 1 & -1.686 & 9.82 & 0 & -21 & 21 \\
\hline Ex-ante perceived social norms - weighted item 2 & -0.61 & 9.106 & 0 & -21 & 21 \\
\hline Ex-ante perceived social norms - weighted item 3 & -1.378 & 5.383 & 0 & -15 & 21 \\
\hline Ex-ante perceived social norms - weighted item 4 & -1.007 & 7.762 & 0 & -21 & 21 \\
\hline Ex-ante perceived behavioral control - item 1 & 4.22 & 1.238 & 4 & 1 & 7 \\
\hline Ex-ante perceived behavioral control - item 2 & 3.706 & 1.316 & 4 & 1 & 7 \\
\hline Ex-ante perceived behavioral control - item 3 & 4.378 & 1.343 & 5 & 1 & 7 \\
\hline Ex-ante perceived behavioral control - item 4 & 3.904 & 1.385 & 4 & 1 & 7 \\
\hline Ex-ante perceived behavioral control - item 5 & 4.435 & 1.143 & 4 & 1 & 7 \\
\hline Ex-ante perceived behavioral control - item 6 & 4.672 & 1.236 & 5 & 1 & 7 \\
\hline Entrepreneur & 0.067 & 0.25 & 0 & 0 & 1 \\
\hline Self-employed parents & 0.484 & 0.5 & 0 & 0 & 1 \\
\hline Prior interest & 3.548 & 1.18 & 4 & 1 & 5 \\
\hline Prior knowledge & 2.684 & 0.994 & 3 & 1 & 5 \\
\hline Time invested by entrepreneur (days) $)^{\ddagger}$ & 0.691 & 1.202 & 0.417 & 0.042 & 10.417 \\
\hline Extraversion & 4.942 & 1.148 & 5 & 1 & 7 \\
\hline Agreeableness & 4.5 & 0.776 & 4.5 & 1 & 7 \\
\hline Conscientiousness & 5.426 & 1.134 & 5.5 & 1 & 7 \\
\hline Emotional stability & 4.742 & 1.155 & 5 & 1 & 7 \\
\hline Openness to experience & 5.462 & 1 & 5.5 & 1 & 7 \\
\hline Peers assessment of desirability & 4.275 & 0.881 & 4.267 & 1 & 6.8 \\
\hline Peers parents self-employed (share) & 0.505 & 0.331 & 0.5 & 0 & 1 \\
\hline Peers are entrepreneurs (share) & 0.065 & 0.148 & 0 & 0 & 1 \\
\hline German & 0.835 & 0.372 & 1 & 0 & 1 \\
\hline Gender $(\mathrm{F}=1)$ & 0.538 & 0.499 & 1 & 0 & 1 \\
\hline Age & 21.699 & 2.211 & 21 & 19 & 34 \\
\hline
\end{tabular}

$\ddagger$ marks variables adjusted for outliers as discussed below.

Prior knowledge and interest We asked students to indicate their interest in and knowledge about entrepreneurship prior to the course.

Time invested by entrepreneur To measure the entrepreneur's commitment, we asked students for an estimate how many hours the founder spent in the joint development of the business plan in total over the whole course duration. We subsequently transformed this variable into a measure for the number of days to ease interpretation in the tables below. In one case a student provided an extreme overestimate of the number of hours. This had an 
effect on the significance of the variable in several regressions. Therefore we reduced the value to the maximal value given by the peers in the student's team. This change did not affect the significance or interpretation of any of the main variables of interest.

Peer variables The peer variables in Table 2 are constructed by taking the peers' mean value for the respective variable without the contribution of the respective focal student. The variable "Peer gender heterogeneity" is one exception: This heterogeneity was calculated using Blau's index (Blau, 1977). Blau's index is calculated as $1-$ $\sum p \cdot i^{2}$, where $p$ is the proportion of peers in a category and $i$ is the number of different categories represented in the peer group (in this case is $i=2$, which means that gender heterogeneity is simply the percentage of the smaller gender representation. Note: We included all ex-ante observations in the calculation of the peer variables, i.e. these values are based on 512 observations and are not affected by a potential non-response bias (see also Table 13).

\subsection{Nonparametric Evidence of Disparate Effects}

It is the main hypothesis of this paper that entrepreneurship education affects perceived entrepreneurship skills and the appraisal of entrepreneurship as a vocation in different ways. In particular, the perception of entrepreneurial ability should increase after a well run course. In contrast, such a course will induce sorting of students with respect to the question whether entrepreneurship is a desirable vocation. This section provides evidence for these hypotheses using nonparametric tests.

Above we argue that the effect of entrepreneurship education on skills can be measured with the help of questions on perceived behavioral control. The vocational effect of entrepreneurship education is measured here through questions on perceived desirability and perceived social norms. In Section 4.3 above we show that these three attitudinal factors are measurable using the items discussed there.

In this section we provide two kinds of analysis: first, we analyze whether the variance of students' perceptions after the course has increased to test for sorting (polarization); second, we analyze whether the entire distribution of students' perceptions has shifted up or down after the course to test for increased or decreased perceptions of desirability or entrepreneurial skill.

We can show that while students' perceptions of their entrepreneurship skills do not display greater variance after the course they are significantly shifted upwards. In contrast, students perceptions of desirability and of social norms are only marginally shifted upwards. Also, students perceptions of the desirability of entrepreneurship display greater ex post variance.

Testing the Sorting Hypothesis Here we test whether students' entrepreneurial intentions and their perceptions of desirability, social norms and behavioral control (skill) show evidence of sorting. Sorting arises if the course causes students to hold stronger, more extreme views in each of these dimensions ex post. Then the variance of their intentions and perceptions should be greater ex post.

The upper half of table 3 below focuses on the intention to found. The results show that students' intentions are more dispersed ex post in three different samples. The effect is statistically significant in one of these. The samples we analyze are: (i) everyone who responded to the question on intentions, (ii) only those students included in the estimation sample and (iii) the subset of these that did not have very extreme ex-ante and ex-post intentions. Note that restricting the samples makes it more difficult to obtain significant results as the number of observations 
is reduced. We feel that excluding students who have stable and extreme intentions as done in sample (iii) is justifiable, as these students cannot demonstrate even more extreme intentions.

The second half of Table 3 provides the same tests using the estimation sample and the sample excluding extreme responses for each of the three attitudinal factors. In each case we provide results for the estimation sample and in parentheses results excluding the most extreme responses. There is strong evidence for sorting of students' perceptions of desirability of entrepreneurship once we exclude the extreme responses. If these are included the measured effect is just insignificant at the $10 \%$ level of significance. In contrast, there is no reliable sorting effect for perceptions of social norms or behavioral control (skills) once we take all three test statistics into consideration $^{12}$.

\section{Table 3: The Variance of Ex ante and Ex post Intentions and Perceptions}

\begin{tabular}{|c|c|c|c|c|}
\hline & & \multicolumn{3}{|c|}{ Standard Deviation of Intentions by Sample } \\
\hline & & Full & Estimation & $\begin{array}{l}\text { Estimation } \\
\text { Restricted }\end{array}$ \\
\hline $\mathbf{N}$ & & 866 & 810 & 692 \\
\hline $\begin{array}{l}\text { Response } \\
\text { time }\end{array}$ & $\begin{array}{l}\text { ex ante } \\
\text { ex post }\end{array}$ & $\begin{array}{l}1.775 \\
1.853\end{array}$ & $\begin{array}{l}1.789 \\
1.860\end{array}$ & $\begin{array}{l}1.499 \\
1.660\end{array}$ \\
\hline \multirow[t]{2}{*}{ Test statistic } & $\begin{array}{l}\text { F-test } \\
\text { Levene's robust test } \\
\text { Brown and Forsythe's } \\
\text { median test }\end{array}$ & $\begin{array}{l}0.186 \\
0.377 \\
0.374\end{array}$ & $\begin{array}{l}0.216 \\
0.451 \\
0.440\end{array}$ & $\begin{array}{l}0.029 \\
0.021 \\
0.070\end{array}$ \\
\hline & & $\begin{array}{r}\mathbf{S t} \\
\text { Desirability }\end{array}$ & $\begin{array}{c}\text { dard Deviatior } \\
\text { Social } \\
\text { Norms }\end{array}$ & $\begin{array}{c}\text { ons by Sample } \\
\text { Behavioral } \\
\text { Control }\end{array}$ \\
\hline $\mathbf{N}$ & & $810 \quad(780)$ & $810 \quad(808)$ & $810 \quad(808)$ \\
\hline $\begin{array}{l}\text { Response } \\
\text { time }\end{array}$ & $\begin{array}{l}\text { ex ante } \\
\text { ex post }\end{array}$ & $\begin{array}{l}1.440(1.351) \\
1.533(1.474)\end{array}$ & $\begin{array}{l}7.370(7.296) \\
7.750(7.687)\end{array}$ & $\begin{array}{l}1.024(1.012) \\
1.085(1.083)\end{array}$ \\
\hline Test statistic & $\begin{array}{l}\text { F-test } \\
\text { Levene's robust test } \\
\text { Brown and Forsythe's } \\
\text { median test }\end{array}$ & $\begin{array}{l}0.106(0.043) \\
0.107(0.047) \\
0.116(0.052)\end{array}$ & $\begin{array}{l}0.156(0.147) \\
0.500(0.484) \\
0.482(0.476)\end{array}$ & $\begin{array}{l}0.123(0.089) \\
0.363(0.315) \\
0.398(0.352)\end{array}$ \\
\hline
\end{tabular}

Note: This table provides tests of increases in the variance of intentions and perceptions. We provide these tests for the full estimation sample and a smaller restricted sample (Results in parentheses in the lower part of the table) from which we remove extreme observations that do not change between the ex ante and ex post surveys. We supplement the F-test based on a Gaussian distributional assumption with Levene's and Brown and Forsythe's less restrictive tests.

Testing the Shift Hypothesis Here we test whether students' intentions and perceptions were shifted upwards or downwards by the course. This would happen if the course caused most students to have stronger or weaker intentions to become entrepreneurs. If so, then we would also expect at least one of the attitudinal factors to show

12 The F-test is based on the assumption of normally distributed responses whereas the other tests are not. 
evidence of a shift of perception. In fact, we observe by far the most significant shift for the perception of behavioral control (skill) as shown in Table 4 below:

To test whether the distribution of students' responses to items measuring the attitudinal factors have shifted upwards or downwards we employ two tests: Wilcoxon's matched pairs signed-rank test and Somers' D measure of association between a treatment dummy and one or more outcome variables. The outcomes are the scales for perceived desirability, perceived social norms and perceived behavioral control which we validated in Table 1 above. The treatment dummy is an indicator for the ex post responses. In case of the Somers' D test we follow Newson (2006) and control for the paired nature of the data by clustering. Whilst the Wilcoxon test provides only p-values for the null hypothesis that the ex ante and ex post distributions of the scales are equal, the Somers' D test also provides confidence intervals for the effect of the course on perceptions.

\section{Table 4: The Location of Ex ante and Ex post Intentions and Perceptions}

\begin{tabular}{|l|ccc|}
\hline & \multicolumn{3}{|c|}{ Perceived } \\
& Desirability & Social Norms & Feasibility \\
\hline Wilcoxon matched-pairs signed-rank test (p-values) & 0.0486 & 0.0022 & 0.0000 \\
Somers'D Coefficient & $0.0938^{*}$ & $0.0864^{\dagger}$ & $0.1901^{* * *}$ \\
Somers'D Standard Error & $(0.0467)$ & $(0.0479)$ & $(0.0459)$ \\
Somers'D 95\% Confidence Interval & $.002-.185$ & $-.008-.180$ & $.100-.280$ \\
\hline \multicolumn{1}{|}{${ }^{\dagger} p<0.10,{ }^{*} p<0.05,{ }^{* *} p<0.01, \quad{ }^{* * *} p<0.001$} &
\end{tabular}

Note: This table provides tests of a shift of the entire distribution of responses when we compare ex post responses to ex ante responses. We report Wilcoxon's matched-pairs signed-rank test and Somers' D test of association to test the effect of the course (treatment) on outcomes.

The Wilcoxon test shows that we can reject the null hypothesis of equality of distributions clearly. This result is confirmed by the Somers' D test which also indicates that students' perceptions of behavioral control have improved between $10 \%$ and $28 \%$ whereas their perceptions of the social norm towards entrepreneurship have even decreased in some cases. The perception of the desirability of entrepreneurship has increased on average but by much less than the perception of behavioral control.

Summary This section has provided a number of tests of the survey instrument used in this study. Here we briefly summarize and comment on our findings in this section.

In Section 4.3 we tested whether the items we use to measure the three attitudinal factors posited by the TPB load on those factors they are intended to measure. In two cases this led us to reject items which did not load on any factor reliably. We also test whether the items loaded on the other factors and found that such loadings were always negligible.

Next we tested whether scales generated from the three sets of items were reliable measures of the latent attitudinal factors. These tests confirmed the usefulness of the items employed.

Finally, in this subsection we analyze how the course changed students' perceptions of the three attitudinal factors. We provide strong evidence that the course increased students' perceptions of their entrepreneurial skills (perceived behavioral control). We also show that the course polarized students' perceptions of the desirability of entrepreneurship.

In the following section we supplement these results with an analysis of the structural equation model set out 
in Section 3 above. We show that the attitudinal factors we subsume under the label vocational attitudinal factors are closely correlated determinants of entrepreneurial intention, whereas the perception of behavioral control is a separate determinant of entrepreneurial intention.

\section{Results from the Structural Equation Model}

This section provides results from estimation of the measurement and latent variable models. Both are estimated using model implied instrumental variables as proposed by Bollen (1996). First, we present results from estimation of the measurement model. With these we analyze whether the latent variables posited by the TPB can be identified. Next, we analyze the latent variable model to test whether the latent variables affect entrepreneurial intentions as predicted by the TPB. Finally, we extend the latent variable model to test whether skill directed and vocational course contents are complements or substitutes.

The measurement model is estimated using the specification set out in equation (4). The results show that items introduced into the questionnaires to measure a specific attitudinal factor of planned behavior usually reflect only that factor. In some cases more than one factor is reflected. However, we are able to identify each attitudinal factor and can determine its effects on entrepreneurial intentions. Overall, the results show that the Theory of Planned Behavior provides a reliable basis for the analysis of entrepreneurship education.

The latent variable model is estimated using the specification set out in Equation (3). The results show that all three attitudinal factors posited by the TPB have a significant positive effect on students' entrepreneurial intentions.

All results reported below have been estimated using a robust estimator of the standard errors. We cluster errors at the level of the groups in which the students undertook small group work in order to control for any common influences within these groups or from the assistants teaching in these groups. There are 36 groups in the data we analyze. The specifications presented in this section are arrived at by testing down from a common general specification. We iteratively eliminated the least significant control variables from these specifications until only a set of significant covariates remained. These are the results we report below.

\subsection{Testing the Measurement Model}

In this section we report results from estimation of the measurement model. We estimate equations for changes in each non-scaling item included in the measurement model. One aim is to test whether the item which is the dependent variable reflects only the latent attitudinal factor suggested by the literature or whether it reflects one or both of the other latent attitudinal factors that are part of the Theory of Planned Behavior as well. Therefore, the model we estimate is general enough to encompass departures from the idealized model as it is presented graphically in Figure 1.

Ogden (2003) and Ajzen and Fishbein (2004) discuss common criticisms of the Theory of Planned Behavior and its empirical applications. The first criticism is that the theory is not testable because authors do not clarify circumstances under which they would consider the Theory of Planned Behavior to have failed. The second criticism is that items constructed to measure latent attitudinal factors and intentions within the Theory of Planned Behavior are so similarly worded as to be indistinguishable. This would make it a foregone conclusion that intentions and attitudinal factors are correlated. 
We address both of these criticisms here. The discussion of the structural equation model in Section 3 above shows that three extreme outcomes from estimation of the measurement model are conceivable: i) all items used to measure the attitudinal factors may correlate with each one of these factors or ii) none may do so and finally iii) items are only correlated to factors they are not intended to measure. Each of these results would provide grounds to reject the applicability of the theory to our data. The results we present below do not fall into any one of these categories. This is consistent with the results of the validity analysis presented in Section 4.3 above.

The second criticism is addressed here too. We find that all of the 10 items we employ are significantly positively correlated to the latent attitudinal factor they measure. Some of these items are also correlated with additional factors but the correlations with these are weaker in all cases but one. Thus we find some evidence of links between the latent factors posited by the TPB. However, this evidence fails to reject identification of the latent factors in our data.

All results presented in this section derive from estimation of the model equations by two stage least squares using GMM. Each equation is estimated twice. First we report results in which we use only the remaining non-scaling items as instruments as suggested by Kirby and Bollen (2009). If the measurement model is correctly specified and the items measuring each attitudinal factor are affected by independent error terms $\delta_{i C}, \delta_{i N}, \delta_{i D}$ (viz. 2), then these instruments should be sufficient to identify each equation that is part of the measurement model. Were some of these instruments to be rejected this would indicate a misspecification of the measurement model as we estimate it. In two cases within the set of items measuring perceived desirability one of the model implied instruments was rejected indicating some additional correlation of items. We discuss this further below. In all remaining cases the main instruments suggested by the model were not rejected.

In addition to the regression suggested by Kirby and Bollen (2009), we provide estimates for each equation in which we augment the set of instruments. By adding additional instruments we test the robustness of the measurement model further. The additional instruments are the ex ante values of the items used to measure the latent attitudinal factors. These values are exogenous as we measure them before the course takes place and they do not measure how students expect the course to affect their attitudes or perceptions. Results from these regressions suggest that the augmented set of instruments is less likely to introduce biases into the estimates we obtain. Using these instruments we find more evidence of interaction between the three attitudinal factors posited by the TPB than we do using only the model implied instruments. As noted above the significant positive correlation of the item and the latent attitudinal factor is given in all cases. In one case a second attitudinal factor is also significantly reflected by an item once we introduce the extended set of instruments.

Overall we do not regard the measurement model as suggested by the TPB to have been rejected by our results. There is an indication of a close connection between the perception of desirability of entrepreneurship and the perceptions of social norms but this does not undermine the model as we discuss in more detail below.

The measurement model set out in section 3 above could be estimated as a system of simultaneous equations which would improve efficiency. We prefer to estimate the model equation by equation in order to be able to employ robust estimators of the standard error of coefficients as well as tests of the instrument sets we employ. Furthermore this allows us to vary the set of instruments such that we can eliminate any instruments rejected by the data.

Perceived Desirability Table 5 below provides results from the regressions explaining differences in students' responses to items 2-5 measuring perceived desirability. In each equation the latent attitudinal factors are measured 
Table 5: Determinants of Perceived Desirability

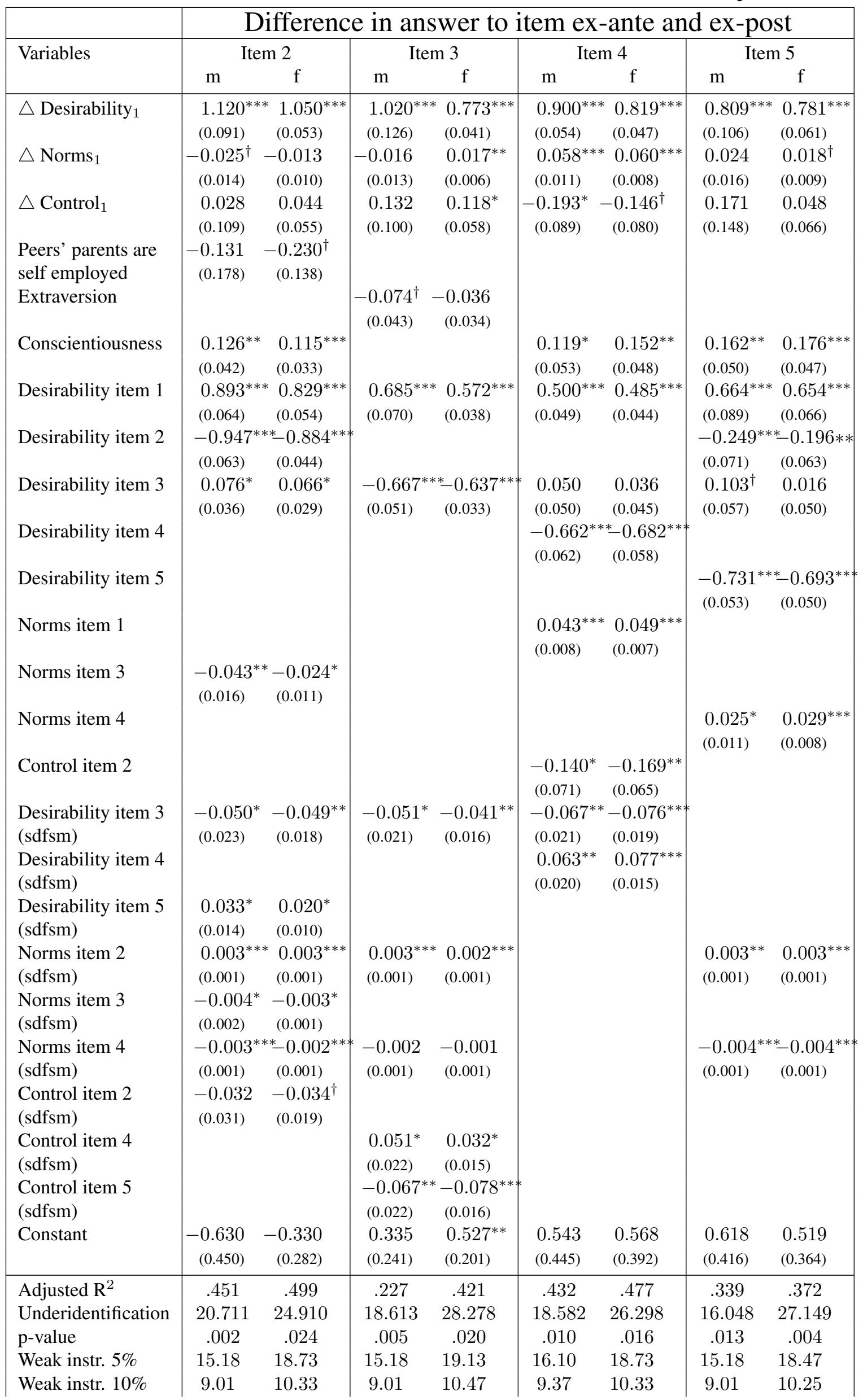


Table 5: Determinants of Perceived Desirability

\begin{tabular}{|c|c|c|c|c|c|c|c|c|}
\hline \multirow{3}{*}{ Variables } & \multicolumn{8}{|c|}{ Difference in answer to item ex-ante and ex-post } \\
\hline & \multicolumn{2}{|c|}{ Item 2} & \multicolumn{2}{|c|}{ Item 3} & \multicolumn{2}{|c|}{ Item 4} & \multicolumn{2}{|c|}{ Item 5} \\
\hline & $\mathrm{m}$ & $\mathrm{f}$ & $\mathrm{m}$ & $\mathrm{f}$ & $\mathrm{m}$ & $\mathrm{f}$ & $\mathrm{m}$ & $\mathrm{f}$ \\
\hline Weak instr. & 12.672 & 14.661 & 9.313 & 27.743 & 6.311 & 16.211 & 5.458 & 18.792 \\
\hline Overident. rest. & 5 & 12 & 4 & 13 & 6 & 12 & 4 & 11 \\
\hline Hansen-J Test & 3.154 & 8.578 & 7.259 & 18.730 & 11.744 & 18.637 & 26.358 & 14.617 \\
\hline$p$-value & .676 & .738 & .202 & .176 & .068 & .098 & .000 & 147 \\
\hline
\end{tabular}

using the first item in the scale for that factor. As noted in Section 3 these measures are endogenous in the measurement model equations. We instrument the measures with two different sets of instruments: first with a set of model implied instruments (m) and second we augment these instruments with the ex ante measures of the items (f). Table 5 provides a separate regression for each item and set of instruments.

We provide measures of the quality of the instruments employed at the bottom of Table 5. These measures show that we can reject underidentification of the endogenous variables at the $1 \%$ or $5 \%$ levels using the Kleibergen and Paap (2006) rk statistic ${ }^{13}$. The Hansen-J Test fails to reject the null hypothesis that the instruments are uncorrelated with the error terms at the $5 \%$ or $10 \%$ levels. Finally, we find that the bias that might be caused by weakness of instruments is below $10 \%$ whenever we use the augmented set of instruments and in the equations for items 3 and 5 it is below $5 \%$. Note that in the equations for item 5 we exclude the difference in item 3 from the set of instruments. This restriction is suggested by the Hansen-J test. Once we eliminate the difference in item 5 as an instrument in the regression for item 3 the underidentification statistic, the weak instruments statistic and the Hansen-J Test statistic all increase. This shows that there is a common factor for items 3 and 5 leading to a violation of the assumption that the errors $\delta_{3 D}$ and $\delta_{5 D}$ are independent.

Each regression contains controls for students' ex ante responses to all items as well as the squared difference of these responses from the scale mean. These variables control for students' ex ante attitudes. We eliminated all insignificant controls iteratively.

Table 5 shows that all four items measuring perceived desirability reflect this latent attitudinal factor. Items 3 and 4 also reflect both of the other latent attitudinal factors perceived social norms and perceived behavioral control. In both these cases the coefficients of perceived desirability are significantly larger than those of the other two latent attitudinal factors. Items 2 and 5 reflect only perceived desirability of entrepreneurship. This shows that variation in perceived desirability can be separately identified with the set of items we employ.

However, the results presented here suggest that perceived desirability is partly affected by perceptions of social norms and behavioral control. As noted by Ajzen and Fishbein (2004) such effects from one attitudinal factor on another are not excluded by the TPB.

Finally, it is interesting to note that changes in the perceived desirability of entrepreneurship are hardly affected by exogenous outside influences such as own family background, gender or nationality. Only one factor exerts strong influence: the student's own conscientiousness. As Heckman et al. (2008) note, Big 5 conscientiousness is the personality trait that predicts outcomes such as grades, leadership performance or longevity better than any other Big 5 personality predictor. Thus it is interesting that it also has significant effects on the perceived desirability of entrepreneurship.

13 We estimate all models in STATA 11.2 using IVREG2 (Baum et al., 2007). Standard errors are cluster and heteroskedasticity robust. We cluster at the team level - cf. Section 4.1. 
Table 6: Determinants of Perceived Social Norms

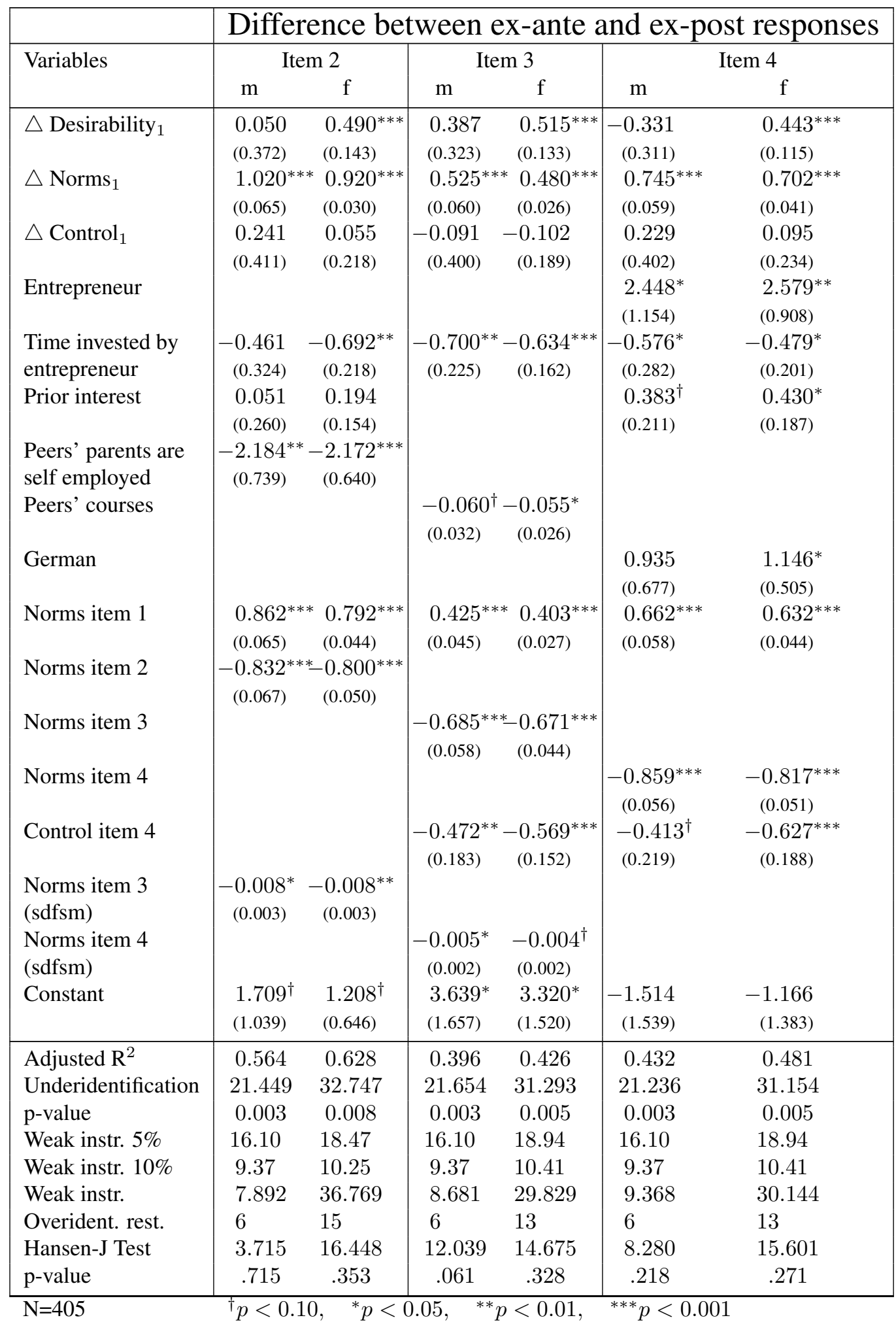

Perceived Social Norms Table 6 provides results from regressions explaining differences in students' responses to items 2-4 measuring perceived social norms. As before the main explanatory variables are differences in the three scaling items: Desirability ${ }_{1}$, Norms $_{1}$ and Control $_{1}$. These variables are endogenous and instrumented as above. Table 6 provides results based just on the model implied instruments $(\mathrm{m})$ and results based on an augmented set of instruments (f).

Tests set out at the bottom of Table 6 indicate that we cannot reject the instruments on the basis of the under- 
identification or the Hansen-J Test. The weak instruments test indicates that the instrumental variables regression introduces only small biases, in all cases these are below $5 \%$. We include the same set of ex ante controls as previously and eliminate all insignificant controls iteratively beginning with the least significant. Note that the model implied instruments are not rejected in any of the regressions.

Table 6 shows that all three items reflect the latent attitudinal factor perceived desirability. All items also reflect perceived desirability once we rely on the augmented set of instruments. In case of item 3 the coefficient reflecting the effect of perceived social norms is as large as the coefficient for perceived desirability. In the other cases the coefficients on the scaling item for social norms are larger and significantly different from those on perceived desirability.

This indicates that social norms are difficult to separate from the perception of desirability in the case of entrepreneurship education. However, we saw previously that perceived desirability can be separately identified from social norms. Furthermore two items measuring perceived social norms reflect these more strongly than perceived desirability. Therefore, we conclude that perceived social norms are separately identifiable from perceived desirability.

Changes in perceived social norms surrounding entrepreneurship are affected by a heterogeneous set of exogenous influences that vary across the three items. These include prior interest in entrepreneurship and whether the student or their peers' parents are active as entrepreneurs. More importantly it emerges that the students' believe less strongly that their environment thinks they should become entrepreneurs the more time the entrepreneur they are matched with during the course invests in interacting with the students. Note that this variable has no effect on perceived desirability or on perceived behavioral control where one might have expected an effect. It seems that interaction with the entrepreneur instills greater awareness of the risks of entrepreneurship in the students. ${ }^{14}$

Perceived Behavioral Control Table 7 below provides results from the regressions explaining differences in students' responses to items 2,3 and 5 measuring perceived behavioral control. As discussed in Section 4 above we removed items 4 and 6 from the scale. Confirmatory factor analysis shows that these items do not reflect the latent construct perceived behavioral control. In the regressions for the measurement model we confirm this result. We do not report these results to save space.

As previously the main explanatory variables are differences in the three scaling items: Desirability ${ }_{1}$, Norms $_{1}$ and $\mathrm{Control}_{1}$. The variables are endogenous and we use the same initial set of instruments as above. Tests set out the bottom of Table 7 indicate that we cannot reject the instruments on the basis of the underidentification or the Hansen-J Test. Also the weak instruments test indicates that the expected bias due to the instruments is around $5 \%$ in two cases and below $10 \%$ in one case. Overall these results are only slightly worse than for the other attitudinal factors.

Table 7 shows that all three items reflect the latent attitudinal factor perceived behavioral control. Items 3 and 5 also reflect the latent factor perceived desirability. The coefficients on the measure of perceived behavioral control are several times greater than the coefficients for perceived desirability in both cases and their difference is statistically significant. Item 2 marginally reflects perceived social norms but the coefficient is very small relative to that on perceived behavioral control. Overall these results show that we can identify perceived behavioral control with the help of the items presented here.

14 We have not found any evidence that entrepreneurs with weaker projects spend more time with students. This might have been an alternative explanation. 
Table 7: Determinants of Perceived Behavioral Control

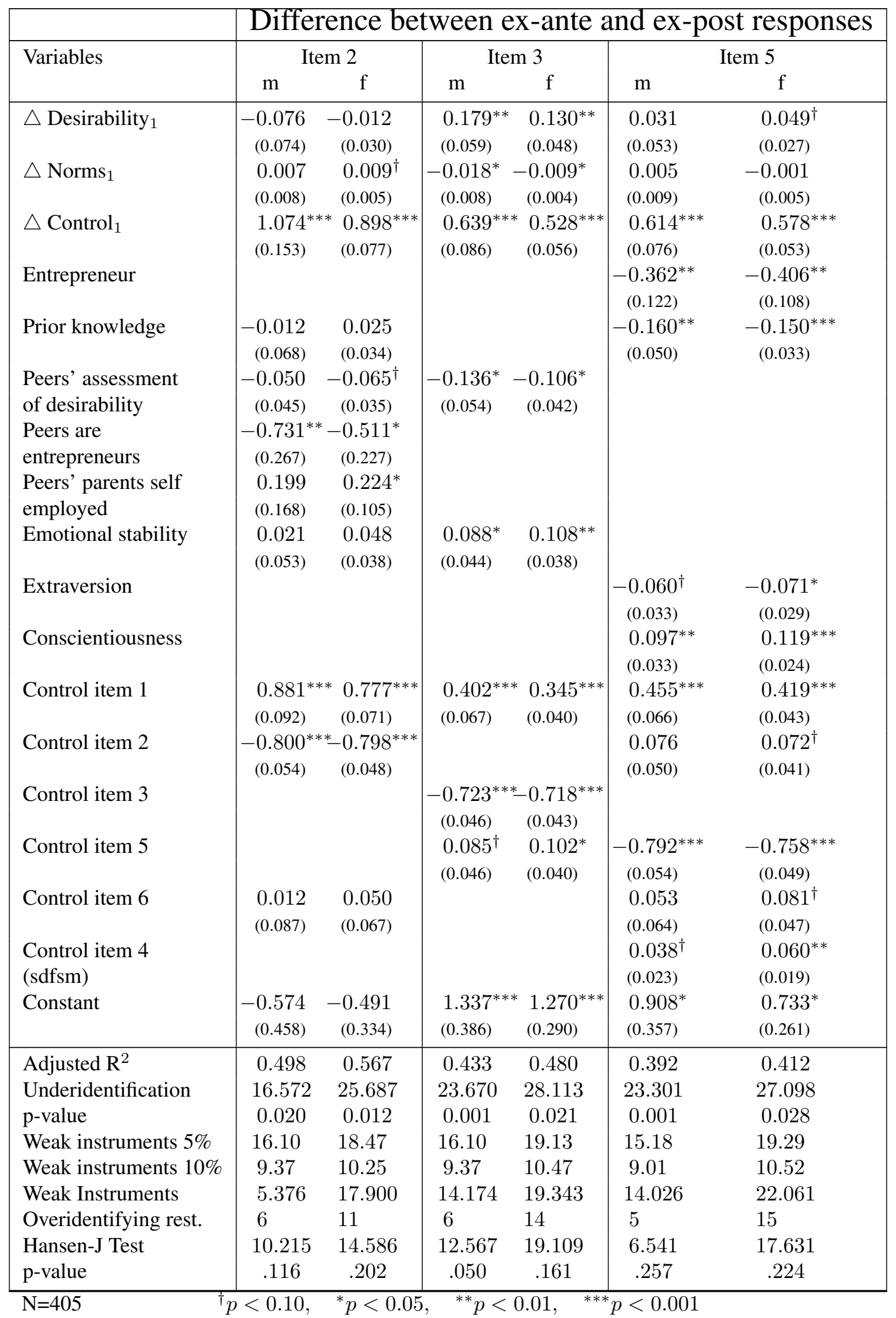

We include the same set of ex ante control variables as previously and eliminated all insignificant control variables iteratively beginning with the least significant. Changes in perceived behavioral control are affected by prior exposure to entrepreneurship through acquaintances, friends and by own experience or interest in the topic. Additionally, peer effects and several personality traits have a significant effect on the perception of behavioral control. 
Assessment of the Measurement Model Returning to the criticisms of previous tests of the Theory of Planned Behavior (Ogden, 2003; Ajzen and Fishbein, 2004) discussed above we find that the items used to measure the three attitudinal factors correlate most strongly with the attitudinal factor they are associated with in the previous literature for ten out of ten items at the five percent significance level. However, items also correlate with attitudinal factors they are not primarily associated with in three out of ten cases if we restrict ourselves to the results based on only the model implied instruments. Regressions based on the augmented set of instruments suggest that students' perceptions of social norms are closely linked to their perceptions of desirability. Here we can identify the coefficients of both attitudinal factors but we are not be able to identify all the variances and covariances in the structural model (Bollen and Davis, 2009). The measurement model emerging from these results is graphically presented in Figure 3 in the appendix. These results support the distinction between the vocational effects of entrepreneurship education and the skill directed effects.

\subsection{The Latent Variable Model}

Here we provide results from estimation of the latent variable model (Equation 3). The dependent variable is the change between students' ex-ante and ex-post entrepreneurial intentions. The main explanatory variables of interest are the latent attitudinal factors perceived desirability, perceived behavioral control and perceived social norms. These variables are endogenous so we use instrumental variables.

Table 8 provides results from estimation of the latent variable model using OLS and instrumental variables estimators. We estimate the instrumental variables regressions by GMM and use model implied instruments (m) as well as an augmented set of instruments (f) as in the previous section. As noted by Bollen (1996) we are free to choose which items define the scaling equations in the structural equation model. Table 8 contains results for two combinations of scaling items. On the left hand side we use the first item from each set of items and on the right hand side we use the second item from each set. We do this to test the robustness of our results to the choice of scaling items.

The results presented in Table 8 show that the OLS estimates of the effects of the attitudinal factors on entrepreneurial intentions are generally biased. The bias is often statistically significant if we compare OLS to the instrumental variables models with the fullest set of instruments (f). These results from the instrumental variables regressions may also be affected by biases, however the weak instruments test shows that these biases are well below 5\%. Furthermore the underidentification test and Hansen's J Test both indicate that we can reject underidentification and that we cannot reject the instruments. Therefore, we rely on the instrumental variables regressions with the full set of instruments (f) in what follows.

Note that the instrumental variables regression which relies solely on the model implied instruments is broadly comparable in outcome to that with the full set of instruments. However, the weak instruments test indicates that results may be slightly more biased than results from the regressions with the full set of instruments. Furthermore results from the two different sets of scaling items are most similar when we use the full set of instruments and are statistically indistinguishable for perceived desirability and perceived behavioral control.

Table 8 shows that all three attitudinal factors have a significant positive effect on entrepreneurial intention. Perceived desirability has the strongest effect on students' intentions, followed by perceived social norms and perceived behavioral control. ${ }^{15}$

15 Note that as a standard deviation change in perceived social norms is six times larger than that in perceived behavioral control, 
Table 8: Results for the Latent Variable Model

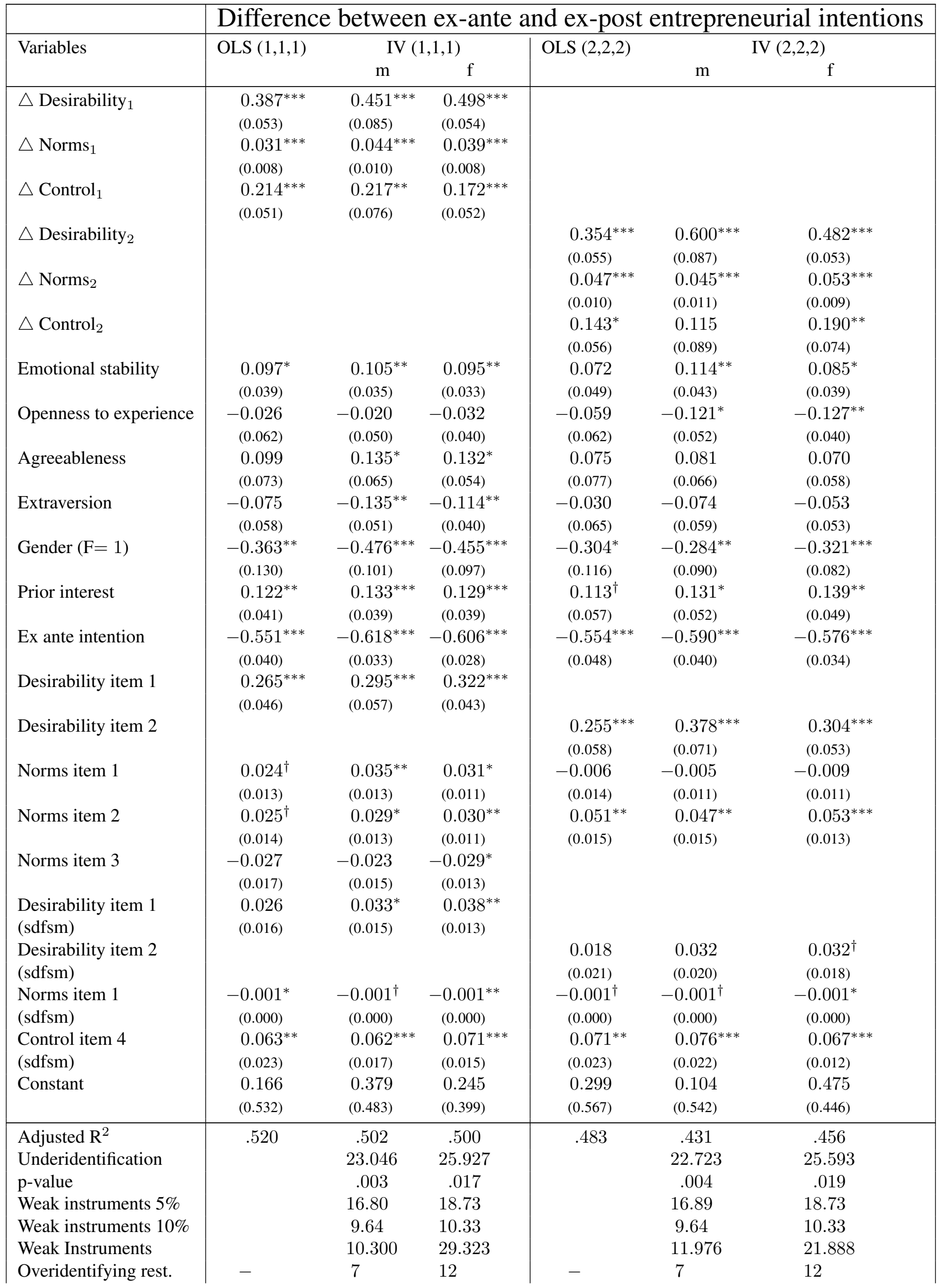

changes in perceived behavioral control have the weakest effect on entrepreneurial intentions. 
Table 8: Results for the Latent Variable Model

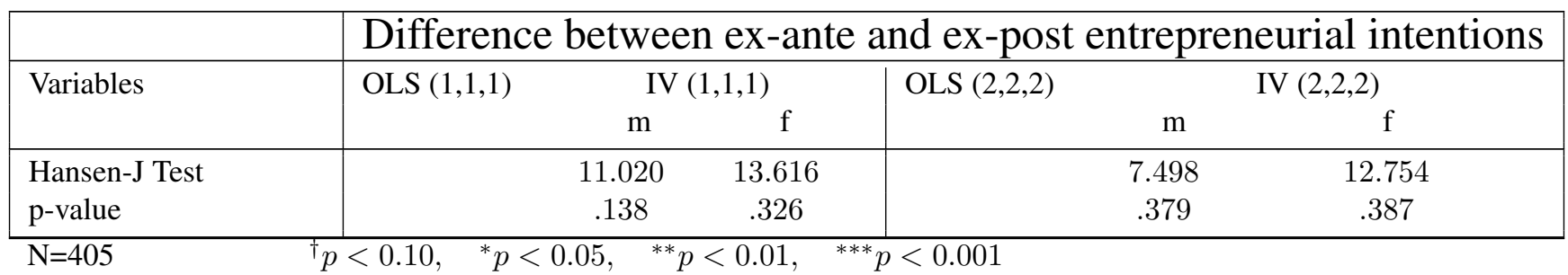

We control for a number of additional influences on students' entrepreneurial intentions. The most important is gender. Women have significantly lower entrepreneurial intentions than men. Also, emotional stability has a stable positive effect on entrepreneurial intentions that is of a comparable size across all regressions and that is not affected by the choice of scaling items. A one standard deviation increase in this measure has an effect that is about half as strong as a one standard deviation increase in perceived behavioral control. Finally, prior interest emerges as having a stable and positively significant effect on students' entrepreneurial intentions as one would expect.

\subsection{Content Complementarity}

Above we show that the latent attitudinal factors posited by the Theory of Planned Behavior can be identified in the data and that positive increases in these factors increase students' entrepreneurial intentions. Figure 2 and Table 3 also showed that students' entrepreneurial intentions become polarized by the course - ex post intentions have greater variance than ex ante intentions.

Here we extend the latent variable model slightly to investigate how interactions of the latent attitudinal factors affect students' entrepreneurial intentions. The extended model includes interaction terms for two of the three combinations of the latent variables. Results including the interaction between perceived desirability and perceived social norms are not presented as this interaction was never significant ${ }^{16}$.

Table 9 below shows that the interaction of perceived desirability and perceived behavioral control is positive and significant once we apply instrumental variables. The result is robust to the choice of scaling items and the estimated coefficient is comparable across the regressions reported in Table $9{ }^{17}$. The size of the effect is quite small however, adding approximately $1 \%$ to the direct effect of perceived behavioral control on entrepreneurial intentions. A test in which we included quadratic terms of the attitudinal factors showed that the result is not due to misspecification of the regression function.

This finding reveals that course content directed at entrepreneurship skills (e.g. business plan writing) and content directed at the vocational decisions of students (e.g. "war stories") complement each other in helping students to form their intention towards entrepreneurship. The strength of the effect is likely to depend on how courses are structured and more work will be necessary to determine how variation in course design affects the complementarity of different course components.

As noted above the course we analyze here contains lectures of successful entrepreneurs as well as a course element in which students work on business plans with entrepreneurs on ongoing ventures. Organizing this course element is costly. The results we provide indicate that it is also valuable - the direct effect of perceived desirability on the formation of entrepreneurial intentions is strong and additionally, there is a significant effect on students'

\footnotetext{
16 Results are available from the authors on request

17 The interaction of perceived social norms and perceived behavioral control is not robust to such controls. Therefore, we do not discuss it any further.
} 
Table 9: Results for the Extended Latent Variable Model

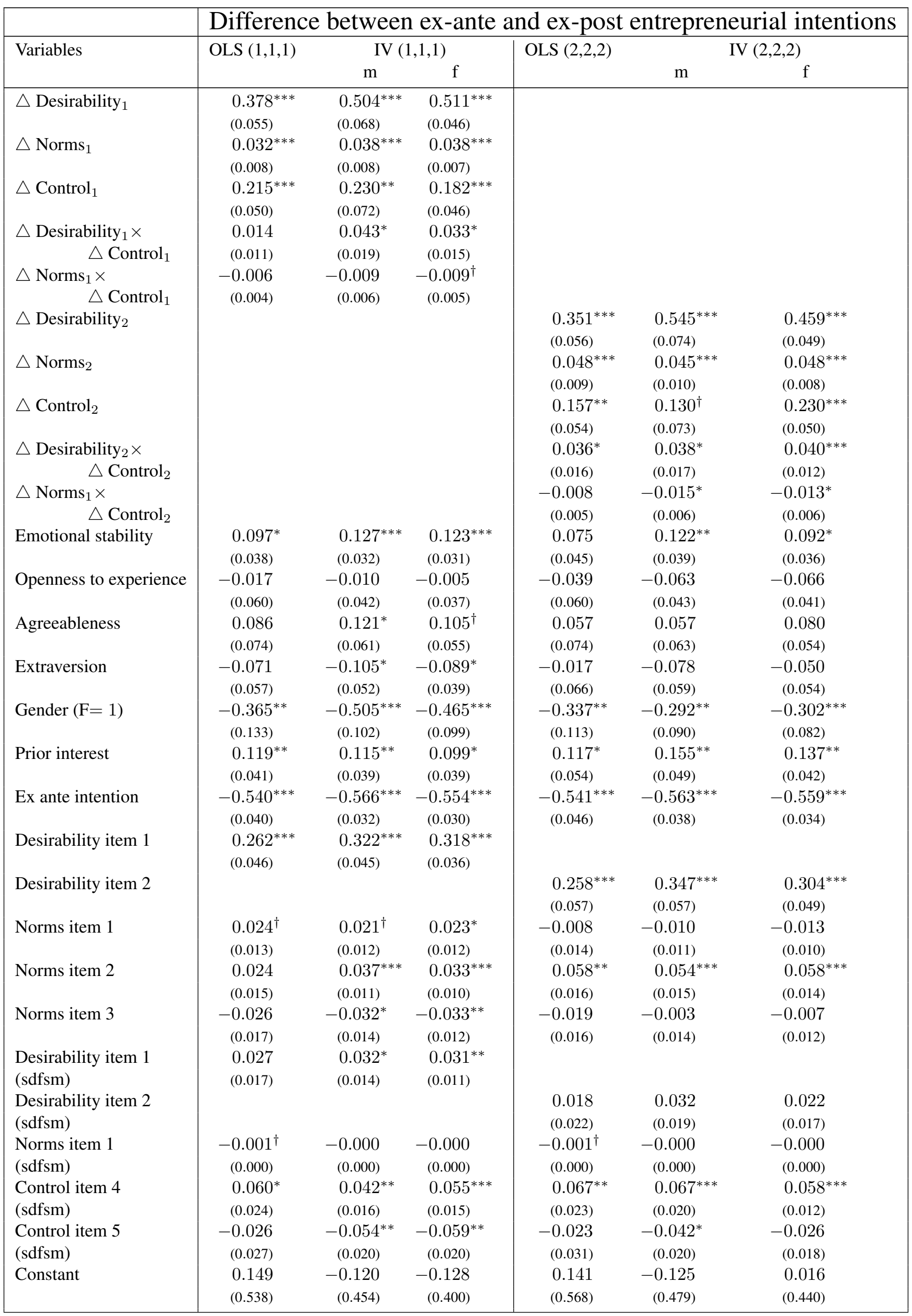




\section{Table 9: Results for the Extended Latent Variable Model}

\begin{tabular}{|c|c|c|c|c|c|c|}
\hline \multirow{3}{*}{ Variables } & \multicolumn{6}{|c|}{ Difference between ex-ante and ex-post entrepreneurial intentions } \\
\hline & \multirow[t]{2}{*}{ OLS $(1,1,1)$} & \multicolumn{2}{|c|}{ IV $(1,1,1)$} & \multirow[t]{2}{*}{ OLS $(2,2,2)$} & \multicolumn{2}{|c|}{ IV $(2,2,2)$} \\
\hline & & $\mathrm{m}$ & $\mathrm{f}$ & & $\mathrm{m}$ & $\mathrm{f}$ \\
\hline Adjusted $\mathrm{R}^{2}$ & .521 & 489 & .497 & 488 & .445 & 464 \\
\hline Underidentification & & 24.173 & 24.172 & & 23.659 & 26.470 \\
\hline p-value & & .012 & .086 & & .014 & .048 \\
\hline Overidentifying rest. & - & 10 & 18 & - & 10 & 16 \\
\hline Hansen-J Test & & 14.181 & 18.526 & & 11.274 & 15.816 \\
\hline p-value & & .165 & .236 & & .337 & .394 \\
\hline
\end{tabular}

ability to benefit from the skill directed course content.

If students' perceptions of the desirability of entrepreneurship become more polarized as indicated by the results set out in Table 3 this counteracts the observed positive shift due to perceived behavioral control that is visible in Table 4. Our data show that the effect of perceived behavioral control only overcomes assessments of desirability (Overly skilled) in marginal cases in which students' perceptions of the desirability of entrepreneurship have fallen very slightly after the course. There are 43 such students in this sample. In contrast, cases in which students' enthusiasm for entrepreneurship is not aligned with their own assessments of their skills (Overly enthusiastic) can occur in students who experience strong reductions in the perception of behavioral control. However, there are only 33 students of this type in the sample and most of them display moderate over-enthusiasm.

Overall we find that both vocational elements of the course and skill directed elements contribute to alterations in students' entrepreneurial intentions. These intentions may increase or fall as a result of the course. There is only a small proportion of students for whom different course components have countervailing effects. In most cases these result in moderate changes of entrepreneurial intentions. This evidence further supports the complementarity of different course components found above.

\section{Conclusion}

This study distinguishes between course content that affects skills and course content that changes students' attitudes to entrepreneurship as a vocation. This distinction is implicit in previous work on entrepreneurship education (Souitaris et al., 2007; Liñán, 2008; Fitzsimmons and Douglas, 2010). In this literature the effects of skill directed course content are measured by items reflecting perceived behavioral control. Additionally, course content affecting students' vocational aspirations is measured by items reflecting perceived social norms and perceived desirability. This paper provides new evidence that this separation of the attitudinal factors into a vocational and a skills dimension has empirical content.

Previous research sometimes shows that entrepreneurship education raises the entrepreneurial intentions of the average student (Souitaris et al., 2007), sometimes the opposite is true (Oosterbeek et al., 2010; von Graevenitz et al., 2010). Additionally, one previous study (Fitzsimmons and Douglas, 2010) shows that vocational course elements are a substitute to course elements that are skill directed. In contrast, this study shows these types of content to be weak complements.

In our view these contradictory findings can be explained if entrepreneurship education has different effects on perceptions of skill than it has on students' vocational aspirations. A well designed entrepreneurship course will 
raise almost all students' perceptions of their own entrepreneurship skills. This is regularly found to be the case in the literature and we find this too. This effect will make even those students more inclined towards entrepreneurship that are not likely to choose entrepreneurship as a vocation. In contrast, the effect of entrepreneurship education on vocational aspirations is primarily to make students' perceptions of the desirability and social norms affecting entrepreneurs more concrete, contributing to more polarized entrepreneurial intentions. This means that the change in the entrepreneurial intention of the average student does not reveal much about the effects of entrepreneurship education. It is to be expected that sometimes this average may increase while at other times it falls. The average is more likely to rise in groups of students that are partly or wholly self selected into entrepreneurship courses as is the case in the sample used by Souitaris et al. (2007).

If entrepreneurship education contributes to sorting would-be entrepreneurs from the remaining students while raising all students' perceptions of their entrepreneurship skills, then these two effects will counteract for students who aspire less to entrepreneurship as a vocation after a course. Depending on what proportion of students is affected by these countervailing effects researchers will find that vocational content and skill directed content of entrepreneurship courses may be complements or substitutes.

Souitaris et al. (2007) argue that entrepreneurship educators should focus on changing "hearts and minds". Our own results suggest a more nuanced approach - entrepreneurship educators must be aware of the sorting function of entrepreneurship education. Entreprenership education should help students choose what they are best suited for. As we find that teaching entrepreneurship skills may reduce some students' ability to make that choice clearly, our findings suggest that skill directed course content should not be emphasized in compulsory entrepreneurship courses taken by students not exposed to the subject previously. In contrast, once students have self selected into a course that seeks to strengthen their previous experience of entrepreneurship our results suggest it is more likely that the skill component and the vocational components will be complements. Our results indicate entrepreneurship skills should receive greater weight in such later courses.

We have sought to minimize the possibility that our results are affected by measurement error, selection bias or attrition bias but the results would be even more convincing if a quasi-experimental approach to the identification of the effects of different types of educational content were adopted. We leave this for future work. Additionally, it would seem important to study the effects of entrepreneurship education over longer periods to further test our conclusions. Finally, additional studies should be conducted at universities and colleges in other cultures and educational settings to provide robustness. 


\section{References}

AjZEN, I. (1985): Action Control: From Cognition to Behavior, Heidelberg, NewYork: Springer, chap. From intentions to actions: A theory of planned behavior, 11-39.

(1987): "Attitudes, traits, and actions: dispositional prediction of behavior in personality and social psychology," Advances in Experimental Social Psychology, 20, 1-63.

(1991): “The Theory of Planned Behavior," Organizational Behavior and Human Decision Processes, 50, 179-211.

AJZEN, I. AND M. FISHBEIN (2004): "Questions raised by a reasoned action approach: comment on Ogden (2003)," Health Psychology, 23, 431-4.

AKerlof, G. AND R. Kranton (2002): "Identity and schooling: Some lessons for the economics of education," Journal of Economic Literature, 40, 1167-1201.

Allgood, S., W. Bosshardt, W. V. D. KlaAuw, and M. Watts (2010): "Economics Coursework and Long-term Behavior and Experiences of College Graduates in Labor Markets and Personal Finance," Economic Inquiry, 1-24.

Anderson, L. W. AND D. R. KRAThwohl, eds. (2001): A Taxonomy for Learning, Teaching, and Assessing: A Revision of Bloom's Taxonomy of Educational Objectives, New York: Longman.

BAGOZZI, R. AND Y. YI (1989): “The degree of intention formation as a moderator of the attitude-behavior relationship," Social Psychology Quarterly, 52, 266-279.

BAndurA, A. (1977): Social Learning Theory, Prentice-Hall.

BAum, C., M. SchafFER, AND S. StILlmAn (2007): "Enhanced routines for instrumental variables/generalized method of moments estimation and testing," Stata Journal, 7, 465-506.

BIRD, B. (1988): “Implementing Entrepreneurial Ideas: The Case for Intention,” Academy of Management Review, $13,442-453$.

Bishop, J. (2006): "Drinking from the fountain of knowledge: Student incentive to study and learn-externalities, information problems and peer pressure," Handbook of the Economics of Education, 2, 909-944.

Blau, P. (1977): Inequality and Heterogeneity: A Primitive Theory of Social Structure, Free Press New York.

Bollen, K. AND W. Davis (2009): “Two Rules of Identification for Structural Equation Models,” Structural Equation Modeling, 16, 523-536.

Bollen, K., J. Kirby, P. Curran, P. Paxton, And F. Chen (2007): "Latent Variable Models Under Misspecification: Two-Stage Least Squares (2SLS) and Maximum Likelihood (ML) Estimators," Sociological Methods \& Research, 36, 48. 
Bollen, K. A. (1996): “An Alternative Two Stage Least Squares (2SLS) Estimator for Latent Variable Equations,” Psychometrika, 61, 109-121.

Bollen, K. A., S. Rabe-Hesketh, And A. Skrondal (2008): “Structural Equation Models," in The Oxford Handbook of Political Methodology, ed. by H. B. Box-Steffensmeier J and D. Collier, oxford University Press, chap. 18, 432-455.

Brockhaus, R. (1980): "Risk Taking Propensity of Entrepreneurs,” Academy of Management Journal, 23, 509_ 520.

Brown, C. AND M. CORCORAN (1997): "Sex-based differences in school content and the male-female wage gap," Journal of Labor Economics, 15, 431-465.

ChalaK, K. AND H. White (2011): "Viewpoint: An extended class of instrumental variables for the estimation of causal effects," Canadian Journal of Economics/Revue canadienne d'économique, 44, 1-51.

Chandler, G. N. And D. W. Lyon (2001): "Issues of Research Design and Construct Measurement in Entrepreneurship Research: The Past Decade.” Entrepreneurship: Theory and Practice, 25, 101-114.

Fayolle, A., B. Gailly, AND N. LASSAS-ClerC (2006): “Assessing the Impact of Entrepreneurship Education Programmes: A New Methodology," Journal of European Industrial Training, 30, 701-720.

FIshbein, M. And I. AjZen (2010): Predicting and Changing Behavior: The Reasoned Action Approach, Psychology Press New York.

FitzSimmons, J. AND E. Douglas (2010): "Interaction between feasibility and desirability in the formation of entrepreneurial intentions," Journal of Business Venturing.

GaGE, N. L. (2009): A Conception of Teaching, Springer-Verlag.

GARDNER, H. (1983): Frames of Mind: The Theory of Multiple Intelligences, Basic Books.

GARTNER, W. (1988): "Who is an Entrepreneur? Is the Wrong Question," American Journal of Small Business, $12,11-32$.

Gosling, S., P. Rentfrow, And W. SwAnn (2003): "A very brief measure of the Big-Five personality domains," Journal of Research in Personality, 37, 504-528.

GUNDRY, L. AND H. WELSCH (2001): “The ambitious entrepreneur High growth strategies of women-owned enterprises," Journal of Business Venturing, 16, 453-470.

Heckman, J., L. Borghans, A. Duckworth, And B. Ter Weel (2008): “The Economics and Psychology of Personality Traits," Journal of Human Resources.

KIRBY, J. AND K. Bollen (2009): "Using Instrumental Variable Tests to Evaluate Model Specification in Latent Variable Structural Equation Models," Sociological Methodology, 39, 327-355. 
KLEIBERGen, F. AND R. PAAP (2006): “Generalized reduced rank tests using the singular value decomposition,” Journal of Econometrics, 133, 97-126.

Kolvereid, L. (1996a): “Organizational Employment versus Self-Employment: Reasons for Career Choice Intentions." Entrepreneurship: Theory and Practice, 20, 23-31.

(1996b): "Prediction of Employment Status Choice Intentions." Entrepreneurship: Theory and Practice, $21,47-57$.

Kolvereid, L. AND E. ISAKSEN (2006): “New Business Start-up and Subsequent Entry into Self-employment," Journal of Business Venturing, 21, 866-885.

KRUEGER, N. (1993): “The impact of prior entrepreneurial exposure on perceptions of new venture feasibility and desirability," Entrepreneurship: Theory and Practice, 18, 5-21.

Krueger, N., M. Reilly, And A. CARsRud (2000): “Competing Models of Entrepreneurial Intentions," Journal of Business Venturing, 15, 411-432.

KuRATKO, D. F. (2005): “The Emergence of Entrepreneurship Education: Development, Trends, and Challenges,” Entrepreneurship Theory and Practice, 29, 577-598.

LiÑÁN, F. (2008): “Skill and Value Perceptions: How Do They Affect Entrepreneurial Intentions?” International Entrepreneurship Management Journal, 4, 257-272.

LiÑÁN, F. AND Y. W. CHEN (2009): "Development and Cross-Cultural Application of a Specific Instrument to Measure Entrepreneurial Intentions," Entrepreneurship: Theory and Practice, 33, 593-617.

Martínez, A. C., J. Levie, D. J. Kelley, R. J. Saemundsson, And T. Sch $\backslash$ ott (2010): A Global Perspective on Entrepreneurship Education and Training, Global Entrepreneurship Monitor.

MONTAÑO, D. E. AND D. KASPRZYK (2008): “Theory of reasoned action, theory of planned behavior, and the integrated behavioral model," in Health Behavior and Health Education, ed. by K. Glanz, B. K. Rimer, and K. Viswanath, San Francisco: Jossey-Bass, chap. 4, 67-96, 4 ed.

NEwson, R. (2006): “Confidence intervals for rank statistics: Somers’ D and extensions,” Stata Journal, 6, 309.

Nunnally, J. C. (1978): Psychometric Theory, McGraw-Hill.

OGden, J. (2003): "Some problems with social cognition models: a pragmatic and conceptual analysis," Health Psychology, 22, 424-8.

Oosterbeek, H., M. van PraAg, AND A. IJSSElstein (2010): “The impact of entrepreneurship education on entrepreneurship skills and motivation," European Economic Review, 54, 442-454.

Oreopoulos, P. And K. G. Salvanes (2011): "Priceless: The Nonpecuniary Benefits of Schooling," Journal of Economic Perspectives, 25, 159-184.

PEARL, J. (1995): “Causal Diagrams for Empirical Research,” Biometrika, 669-688. 
(2009): Causality: models, reasoning and inference, Cambridge Univ Press, 2 ed.

(2012): “The Causal Foundations of Structural Equation Modeling," in The Handbook of Structural Equation Modeling, ed. by R. Hoyle, Guilford Press.

REvelle, W. AND R. Zinbarg (2009): “Coefficients $\alpha, \beta, \omega_{H}$, and the GLB: Comments on Sijtsma,” Psychometrika, 74, 145-154.

Robinson, P., D. Stimpson, J. Huefner, And H. Hunt (1991): "An Attitude Approach to the Prediction of Entrepreneurship," Entrepreneurship Theory and Practice, 15, 13-31.

Scherer, R., J. Adams, S. Carley, And F. Wiebe (1989): "Role Model Performance Effects on Development of Entrepreneurial Careerc preference," Entrepreneurship Theory and Practice, 13, 53-71.

SHAH, R. AND S. GOLDSTEIN (2006): "Use of structural equation modeling in operations management research: Looking back and forward," Journal of Operations Management, 24, 148-169.

Shane, S. (2009): "Why Encouraging More People to Become Entrepreneurs is Bad Public Policy," Small Business Economics, 33, 141-149.

Shapero, A. And L. Sokol (1982): Encyclopaedia of Entrepreneurship, Prentice Hall, chap. The social dimensions of entrepreneurship.

Sheshinski, E., R. Strom, And W. BAumol (2007): Entrepreneurship, Innovation, and the Growth Mechanism of the Free-enterprise Economies, Princeton University Press.

Souitaris, V., S. Zerbinati, And A. Al-Laham (2007): "Do Entrepreneurship Programmes Raise Entrepreneurial Intention of Science and Engineering Students? The Effect of Learning, Inspiration and Resources," Journal of Business Venturing, 22, 566-591.

Stock, J. AND M. Yogo (2002): “Testing for weak instruments in linear IV regression,” NBER Working Paper.

TKACHEV, A. AND L. KolvereID (1999): “Self-employment intentions among Russian students," Entrepreneurship \& Regional Development, 11, 269-280.

VOn Graevenitz, G., D. Harhoff, And R. Weber (2010): “The Effects of Entrepreneurship Education,” Journal of Economic Behavior \& Organization, 76, 90-112.

White, H. And X. Lu (2011): "Causal Diagrams for Treatment Effect Estimation with Application to Efficient Covariate Selection," The Review of Economics and Statistics, 93, 1453-1459.

Zinbarg, R., W. Revelle, I. Yovel, And W. Li (2005): “Cronbach's $\alpha$, Revelle's $\beta$, and Mcdonald's $\omega_{H}$ : Their Relations With Each Other and Two Alternative Conceptualizations of Reliability," Psychometrika, 70, $123-133$. 


\section{Appendix}

\subsection{Further Empirical Evidence Supporting TPB}

Here we provide two sets of results that support our use of the TPB in this study. We provide evidence in support of using intentions as an outcome measure. Additionally, we provide evidence that the attitudinal factor perceived behavioral control is a good measure of skills imparted by the course we study.

Intentions As discussed in Section 2 we are constrained to using intentions as an outcome measure, because we do not observe the longer term entrepreneurial activities of the students after the entrepreneurship course we study. However, we do observe one outcome which takes place soon after the students have provided their ex post answers to our survey: their results in a business plan competition.

In Table 10 we analyze how the probability of receiving a prize in this business plan competition depends on students' entrepreneurial intentions. The table provides results from linear probability models as well as from a probit regression. The regressions contain our measure of intentions as well as a number of covariates that significantly affect students' success in the business plan competition. We iteratively tested down to this specification from a more extensive specification including the same covariates as the regressions reported above.

\section{Table 10: Verifying the Intentions Measure}

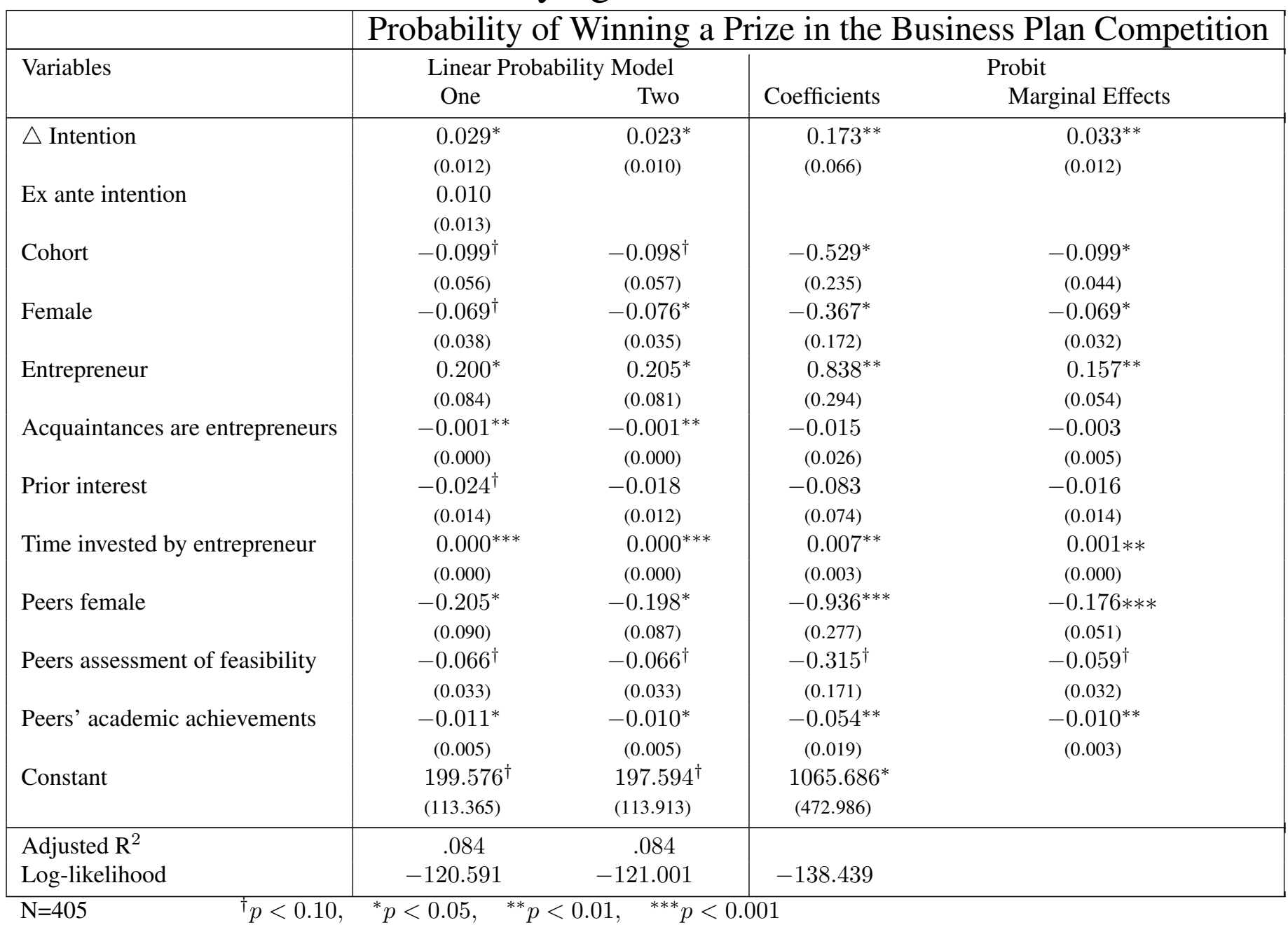

We find that the change in students' entrepreneurial intentions resulting from the course has a significant positive 
effect on their probability of winning a prize at the business plan competition. In results not reported below we also find that the attitudinal factors posited by the TPB are not significant if added to the regressions reported in Table 10. This shows that the model of the TPB in which entrepreneurial intentions determine entrepreneurial activity can be verified in our data at least in the short run.

Perceived Behavioral Control Our analysis relies on the assumption that the difference in perceived behavioral control measures changes in students' skills that result from the entrepreneurship course. Here we use a set of additional questions relating directly to such skills to show that a scale based on those questions correlates strongly with the difference in perceived behavioral control.

We ask students 20 questions ${ }^{18}$ related to their ability to undertake tasks that are related to setting up and running a business. These include the ability to identify opportunities, abilities to evaluate risks and build networks as well as their perseverance. These questions were asked before and after the course. We construct two scales capturing these business skills ex ante and ex post ${ }^{19}$. Then we difference the scales and correlated these differences with the differences in the scales for the three attitudinal factors derived form the TPB.

Table 11 provides correlations between all of the scales as well as p-values for the null hypothesis that the correlations are zero. The table shows two things: first, the business skills measure correlates much more strongly with the scale for perceived behavioral control than with either of the other two scales; second, the scales for perceived desirability and perceived social norms also correlate very strongly with one another.

\section{Table 11: Cross-correlation of Attitudinal Factors}

\begin{tabular}{|l|cccc|}
\hline Difference in & Difference in & \multicolumn{3}{c|}{ Difference in perceived } \\
& business skills & behavioral control & desirability & social norms \\
\hline business skills & 1.000 & & & \\
perceived behavioral control & $\mathbf{0 . 4 2 9}$ & 1.000 & & \\
& $(0.000)$ & & & \\
perceived desirability & 0.227 & 0.329 & 1.000 & \\
& $(0.000)$ & $(0.000)$ & & 1.000 \\
perceived social norms & 0.182 & 0.296 & $\mathbf{0 . 4 0 7}$ & \\
& $(0.000)$ & $(0.000)$ & $(0.000)$ & \\
\hline
\end{tabular}

This is further evidence that the effects of entrepreneurship education on students' skills and on their assessment of entrepreneurship as a vocation can be separately identified.

\subsection{Sample Selection and Non Response Bias}

Here we provide tests for sample selection and non-response bias. We can show that the sample is randomly selected in three dimensions. 784 of the 814 enrolled students provided data on gender and the number of courses passed prior to taking part in the "Business Planning" course. Additionally, we know which cohort the students come from. To test for sample selection we estimate a probit model. In this model the dependent variable is equal to one if an individual returned completed ex-ante and ex-post questionnaires (405 students) and zero otherwise. We

18 The list of items is available from the authors upon request.

19 Cronbach's $\alpha$ for these two scales is in excess of 0.95 . 
test whether the cohort, the number of courses passed and gender can explain full participation in the two surveys.

\begin{tabular}{|c|c|c|}
\hline & \multicolumn{2}{|c|}{$\mathbf{D}(=1)$ if matched and valid questionnaire } \\
\hline & Coefficients & Marginal effects \\
\hline \multirow{4}{*}{$\begin{array}{l}\text { Courses } \\
\text { passed } \\
\text { Gender }(\mathrm{F}=1)\end{array}$} & $0.022^{* * *}$ & $0.009^{* * *}$ \\
\hline & (0.003) & $(0.001)$ \\
\hline & -0.016 & -0.006 \\
\hline & $(0.096)$ & $(0.038)$ \\
\hline \multirow{2}{*}{ Cohort $(2009=1)$} & $1.205^{* * *}$ & $0.452^{* * *}$ \\
\hline & $(0.104)$ & $(0.0345)$ \\
\hline \multirow[t]{2}{*}{ Constant } & $-1.484^{* * *}$ & \\
\hline & $(0.182)$ & \\
\hline Log-likelihood & -463.090 & \\
\hline $\mathrm{N}$ & 784 & \\
\hline
\end{tabular}

Results are presented in Table 12. The student's number of courses passed increases the likelihood of response in both survey rounds, while the effect of gender is not statistically significant at the $1 \%$ level. This may reflect greater pressures acting on students with less progress in their studies making them less willing to invest time to answer in both survey rounds. The number of courses passed does not significantly affect results in our analysis above. As we could not determine team membership in all cases we drop some observations in cohort 1 . Therefore the dummy for the 2009 cohort is also highly significant. ${ }^{20}$

\begin{tabular}{|c|c|c|c|c|c|}
\hline \multirow[b]{2}{*}{ Variables } & & \multicolumn{2}{|c|}{ subgroup } & \multicolumn{2}{|c|}{ test statistic } \\
\hline & & $\begin{array}{l}\text { pre-survey only } \\
\quad(N=189)\end{array}$ & $\begin{array}{c}\text { both surveys } \\
(N=405)\end{array}$ & $|\mathbf{t}|$ & p-value \\
\hline Age & (years) & 22.1 & 21.7 & 2.001 & 0.004 \\
\hline Gender $(\mathrm{F}=1)$ & $(\%)$ & 59.2 & 53.8 & 1.330 & 0.184 \\
\hline German & $(\%)$ & 71.7 & 83.5 & 3.567 & 0.000 \\
\hline Courses passed & & 41.2 & 45.3 & 2.872 & 0.004 \\
\hline Parent(s) self-employed & $(\%)$ & 51.3 & 48.4 & 0.777 & 0.437 \\
\hline Acquaintance(s) self-employed & (count) & 1.9 & 3.3 & 0.529 & 0.299 \\
\hline Entrepreneur & $(\%)$ & 0.09 & 0.07 & 1.541 & 0.124 \\
\hline Ex-ante intention & & 4.24 & 4.19 & 0.375 & 0.708 \\
\hline Ex-ante desirability & & 4.35 & 4.29 & 0.610 & 0.542 \\
\hline Ex-ante social norms & & -4.61 & -4.68 & 0.081 & 0.936 \\
\hline Ex-ante behavioral control & & 4.20 & 4.22 & 0.138 & 0.890 \\
\hline
\end{tabular}

Next, we investigate the response behavior to both surveys. In addition to the 405 matched ex-ante and ex-post questionnaires we received 189 valid ex-ante-only questionnaires. Table 13 provides demographic variables as well as the ex-ante values of the variables of the TPB for these two groups. The table shows that students who are performing relatively badly during their studies, older students and students with a nationality other than German more often failed to complete the ex-post test.

The most important finding from Table 13 is that the mean of the dependent variables for those responding only to the first or to both questionnaires is statistically indistinguishable. This shows that the demographic departures from a representative sample that we see in the table above do not introduce a measurable non-response bias in the

20 If we drop the number of courses passed variable we can include the missing observations in the regression and the cohort dummy is no longer significant. 
dependent variables.

\subsection{Additional Figures}

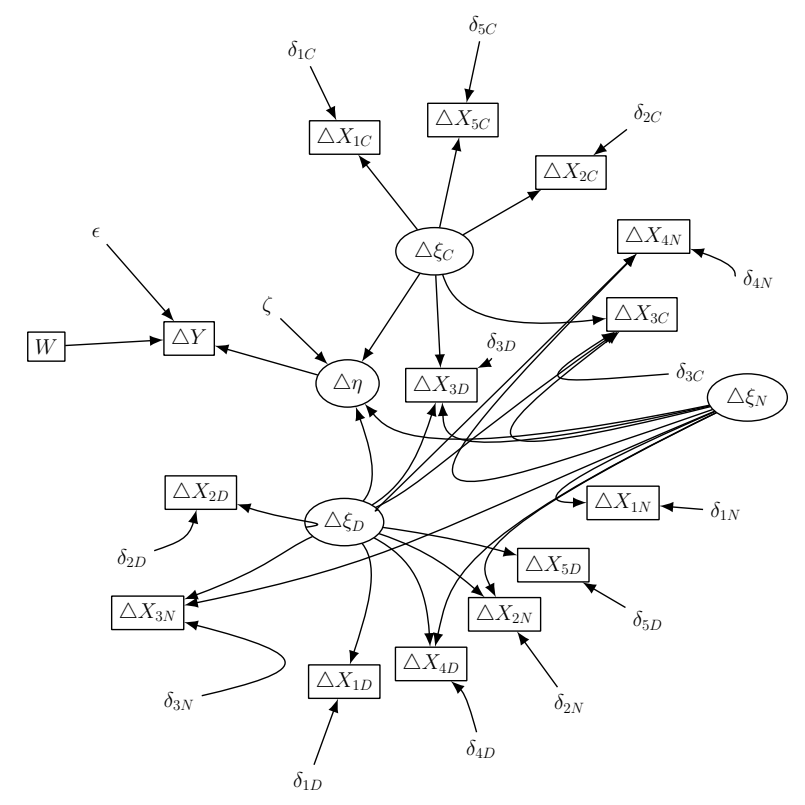

Figure 3: Path Diagram of the Estimated Structural Equation Model

Note: This figure sets out the causal relationships in the structural equation model estimated in this paper. Variables presented in circles are latent variables: $\eta$ - entrepreneurial intention and $\xi_{D}$ perceived desirability, $\xi_{N}$ perceived social norms, $\xi_{C}$ perceived behavioral control. Variables in squares are observed items, e.g. $X_{10}$ or exogenous variables, e.g. $W$. All remaining variables are i.i.d. error terms, e.g. $\epsilon$ or $\delta_{1}$.

Omega

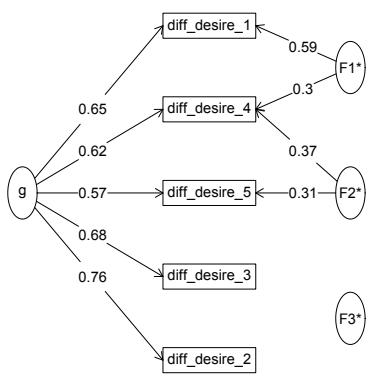

Omega

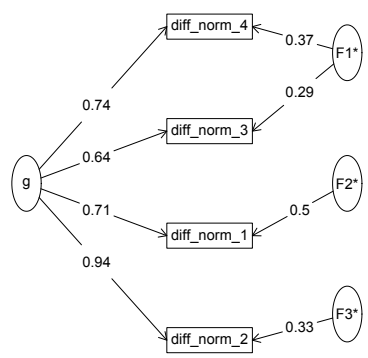

Omega

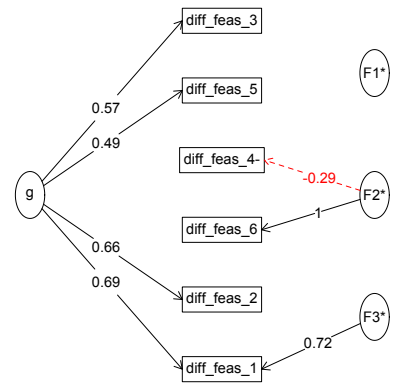

Figure 4: General Factor Saturation of Items Measuring Perceived Desirability, Perceived Social Norms and Perceived Behavioral Control 